\title{
Acoustic evidence for right-edge prominence in Nafsan ${ }^{\text {a) }}$
}

\author{
Rosey Billington, ${ }^{\text {b) }}$ Janet Fletcher, ${ }^{\text {c) }}$ Nick Thieberger, ${ }^{\text {d) }}$ and Ben Volchok \\ ARC Centre of Excellence for the Dynamics of Language, School of Languages and Linguistics, The University of Melbourne, Melbourne, \\ Victoria 3052, Australia
}

\begin{abstract}
:
Oceanic languages are often described as preferring primary stress on penultimate syllables, but detailed surveys show that many different types of prominence patterns have been reported across and within Oceanic language families. In some cases, these interact with segmental and phonotactic factors, such as syllable weight. The range of Oceanic prominence patterns is exemplified across Vanuatu, a linguistically diverse archipelago with over 130 languages. However, both impressionistic and instrumentally-based descriptions of prosodic patterns and their correlates are limited for languages of this region. This paper investigates prominence in Nafsan, an Oceanic language of Vanuatu for which previous observations of prominence differ. Acoustic and durational results for disyllabic and trisyllabic Nafsan words show a clear pattern of higher fundamental frequency values in final syllables, regardless of vowel length, pointing towards a preference for prominence at the right edge of words. Short vowels also show centralisation in penultimate syllables, providing supporting evidence for right-edge prominence and informing the understanding of vowel deletion processes in Nafsan. (c) 2020 Acoustical Society of America. https://doi.org/10.1121/10.0000995
\end{abstract}

(Received 3 May 2019; revised 15 September 2019; accepted 16 October 2019; published online 30 April 2020)

[Editor: Benjamin V. Tucker]

Pages: $2829-2844$

\section{INTRODUCTION}

This paper investigates prominence in Nafsan (South Efate), a Southern Oceanic language spoken by an estimated 6000 people in three villages (Erakor, Eratap, and Pango) on the island of Efate in Vanuatu. The phonology of Nafsan has been discussed in comparative and descriptive work (Clark, 1985; Lynch, 2000c; Thieberger, 2006), but for some aspects of the segmental and prosodic system there have been different views and some challenges to identifying clear patterns. In particular, until very recently there have been open questions relating to whether there is a vowel length distinction in the language, why some vowels undergo deletion, and what patterns of word- and phraselevel prosodic prominence are used. There are also indications that there are crucial interactions between vowel distinctions, vowel deletion, and prominence patterns, and that these therefore need to be considered together in order to adequately describe the sound system of Nafsan. For example, it has been proposed that the major factors influencing vowel deletion in Nafsan are phonemic vowel length and proximity to an accented syllable, based on impressions that final syllables have accentual prominence (Billington et al., 2020), but these impressions differ from some previous observations and have not been verified

a) Portions of this work were presented at the 17th Australasian International Speech Science and Technology Conference, Sydney, Australia, December 2018.

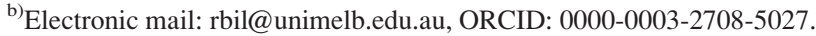

${ }^{c)}$ ORCID: 0000-0001-7223-4533.

d) ORCID: 0000-0001-8797-1018. empirically. The present study is part of a wider project using instrumental phonetic approaches to investigate various aspects of Nafsan phonology. Here, we examine prominence patterns observable at the lexical level in Nafsan, focusing on whether there is evidence that syllables are more prominent when they occur at the right edge. We identify the acoustic cues associated with prominence patterns, and discuss how the findings relating to prominence inform other aspects of the Nafsan sound system.

\section{A. Prominence in Oceanic languages}

For Oceanic languages, and Austronesian languages more generally, comprehensive descriptions of prosodic patterns (based on auditory impressions or instrumental investigations) are scarce (Himmelmann and Kaufman, 2020). At the lexical level, Oceanic languages are often described as preferring primary stress on penultimate syllables (Lynch et al., 2002; Ross, 1998). However, crosslinguistic examinations suggest that this tendency may not be as widespread as previously thought, with a range of patterns observed across Oceanic languages (Lynch, 2000b), including among the more than 130 Southern Oceanic languages of Vanuatu. ${ }^{1}$ While some languages of Vanuatu are described as having regular penultimate stress, such as Erromangan (Crowley, 1998, p. 17), many are described as having a weight-sensitive system whereby stress is penultimate unless the final syllable contains a coda consonant, as in Tamambo (Riehl and Jauncey, 2005, p. 258), and/or a long vowel or diphthong, as in Naman (Crowley, 2006, p. 39 ), in which case stress is final. Some languages are 
reported to have a reliably final stress pattern, such as Vurës (Malau, 2016, p. 38), while others may only have final stress if a word-final vowel has been deleted, as in Lelepa (Lacrampe, 2014). Very occasionally, antepenultimate stress is suggested, as in Nguna (Schütz, 1969, p. 11), and in other cases stress may be lexically contrastive, as in Paamese (Crowley, 1982, p. 19). Some grammatical descriptions note prominence patterns which suggest phrasal accent rather than lexical stress, for example in Nahavaq (Dimock, 2009, pp. 46-55), Daakaka (von Prince, 2015, pp. 34-40), and Mwotlap (François, 2001, p. 81). Given the different hypotheses regarding the status of stress in these languages, we use the more general term prominence in this paper.

There is increasing interest in developing instrumentallybased descriptions of word-, phrase-, and utterance-level prosodic patterns in Oceanic languages, as can be seen in recent research on Central Pacific languages of Polynesia such as Samoan (Calhoun, 2015, 2017; Yu and Stabler, 2017; Zuraw et al., 2014), Māori (Mixdorff et al., 2018; Thompson et al., 2011), Tongan (Garellek and White, 2015; Kuo and Vicenik, 2012), and Niuean (Clemens, 2014, 2019). There are also some prosodic analyses of languages from other Oceanic groups, such as the Northwest Solomonic language Torau, of Papua New Guinea (Jepson, 2014), the Southeast Solomonic language Gela (Simard and Wegener, 2017), from the Solomon Islands, and the Southern Oceanic language Drehu, of New Caledonia (Torres et al., 2018). For the languages of Vanuatu, there are some phonetically-based explorations of prosodic patterns, such as for Nahavaq (Dimock, 2009, pp. 46-55), Daakaka (von Prince, 2015, pp. 34-40), and Mavea (Guérin, 2019), but for most languages, prosodic descriptions are limited to impressionistic comments relating to word stress or lexical prominence, with little information regarding how these might be realised. Existing descriptions also have limited scope for examining how prominence phenomena interact with other aspects of a language's phonology. This is of particular interest in the Vanuatu context, given that beyond the variety of attested prominence patterns, the languages of Vanuatu also show striking diversity in their segmental inventories and phonotactic structures.

Crosslinguistically, a range of acoustic and durational cues correlate with lexical stress, though much of the instrumental phonetic research on stress has focused on languages with similar genetic and typological profiles. Overviews of production patterns in Germanic languages such as English and Dutch, and to a lesser extent languages from elsewhere in Europe, show that correlates of stress include higher fundamental frequency, increased loudness/intensity, increased vowel duration, and more peripheral vowel quality for stressed compared to unstressed syllables (Lehiste, 1970; van Heuven, 2019; van Heuven and Sluijter, 1996; van Heuven and Turk, 2020). In a survey of acoustic correlates of stress in 75 languages from a range of language families around the world, Gordon and Roettger (2017) find that duration is most widely attested as a primary correlate. These various correlates are also drawn on as auditory cues, for example, as seen in perceptual studies undertaken with speakers of Germanic languages (Cutler, 2005; van Heuven, 2019). The particular cue or combination of cues associated with lexical stress is language-specific, and may depend to some extent on other language-specific phonological properties. Some comparisons across languages suggest that cues to stress may be more robust and consistent in languages for which stress patterns are lexically contrastive, and thereby not predictable, compared to languages with fixed lexical stress patterns, for example, as noted by Dogil and Williams (1999) with reference to data for Lithuanian, Polish, German, and Spanish and by Vogel et al. (2016) with reference to data for Hungarian, Turkish, Greek, and Spanish. It has also been argued that for languages in which a suprasegmental property is used contrastively, for example, where duration signals phonemic vowel length, this suprasegmental property will not be used as a primary perceptual cue to lexical stress (Berinstein, 1979). This idea has been interpreted as a prediction relating to patterns of production as well as perception. Although an overview of reported correlates of lexical stress in descriptions of 140 languages finds limited crosslinguistic evidence for such a relationship (Lunden et al., 2017), there are individual languages for which phonetic data suggests this may be relevant, for example Hungarian, which has a vowel length contrast and for which duration is not a correlate of lexical stress (Vogel et al., 2016). Other types of language-specific restrictions on the ways suprasegmental cues can be combined have also been found, for example, in the co-occurrence restrictions between tones and vowels in Maastricht Limburgish (Gussenhoven, 2012). Phonotactic factors may also be relevant to both the assignment and realisation of lexical stress; syllable weight plays a role in determining stress location in many languages around the world (Goedemans, 2010), and it has been argued that in such languages, syllables with long vowels or codas are phonetically well-suited to bearing lexical stress due to not just the additional segmental material in a syllable rhyme but the distinctiveness of the overall energy profile of these syllables (Gordon, 2002).

In the Asia-Pacific region, phonetic investigations of lexical stress in Austronesian languages point towards main correlates such as increased fundamental frequency and intensity for Besemah Malay (McDonnell, 2016), increased duration, fundamental frequency movement, vowel quality differences, and spectral tilt for Papuan Malay (Kaland, 2019), and increased fundamental frequency and duration for primary stress in Tongan, together with other intensity and spectral differences (Garellek and White, 2015). Among descriptions of the languages of Vanuatu, impressionistic correlates of stress reported in the literature include duration in Tamambo (Riehl and Jauncey, 2005, p. 258), loudness, duration, and vowel quality in Sakao (Guy, 1974, pp. 12-17), duration, pitch, and intensity in Lelepa (Lacrampe, 2014, p. 58), intensity and duration in Maskelynes (Healey, 2013, p. 32), and loudness and pitch in Anejom (Lynch, 2000a, p. 24). Anejom is suggested to be an example of a language which has a phonemic length distinction in the vowel system and does not use duration as a cue to stress 
(Lunden et al., 2017, p. 567). For Lelepa, which has a length contrast for some vowel qualities, exploratory duration measurements indicate that increased vowel duration may correlate with stress, but most noticeably among short vowels (Lacrampe, 2014, pp. 38-41).

\section{B. The sound system of Nafsan}

The consonant inventory of Nafsan includes a contrast at four places of articulation for stops $/ \mathrm{kp} \mathrm{p} \mathrm{t} \mathrm{k/} \mathrm{and} \mathrm{nasals}$ $/ \mathrm{gm} \mathrm{m} \mathrm{n} \mathrm{y} /$, and two fricatives /f/ and /s/. There is no voicing distinction among the obstruents. Sonorants include a trill $/ \mathrm{r} /$, prenasalised trill $/ \mathrm{n}^{\mathrm{d}} \mathrm{r} /$, lateral $/ \mathrm{l} /$, and glides $/ \mathrm{w} /$ and /j/ (Thieberger, 2006, p. 46). There is a contrast between vowels of five qualities (Thieberger, 2006, p. 54). The possibility of a length distinction has been mentioned in passing in previous historical-comparative work (Clark, 1985; Lynch, 2000c), but long vowels do not feature in major descriptive work on the language (Thieberger, 2006), nor in other materials published in or about the language apart from the occasional occurrence of orthographic representations with doubled vowels (e.g., Tryon, 1976). However, through recent dictionary workshops and collaborative work with community members (e.g., Krajinović et al., 2019), analyses of archival wordlist data (Billington et al., 2020), and ongoing targeted investigations of monosyllabic words using new acoustic phonetic data, there is now evidence for a monophthong inventory comprising /i, is, e, e:, a, a:, o, o:, $\mathrm{u}, \mathrm{u}: /$. Each of the five vowel qualities may occur either phonemically short or long, in various syllable types. At least in CVC syllables, long vowels are close to twice as long as short vowels, and the duration difference between long and short vowels is approximately the same across all vowel qualities. There are also indications that long vowels are slightly, but not substantially, more peripheral than corresponding short vowels in the acoustic space.

Nafsan phonotactic patterns are notably complex compared to patterns for languages spoken further to the north in Vanuatu, and compared to the typological preference for $\mathrm{CV}$ syllables among Oceanic languages (Lynch, 2000c; Lynch et al., 2002). Complex codas do not occur, but the language exhibits a range of heterorganic consonant clusters in syllable onsets, with various possible sonority profiles (Thieberger, 2006). There is a relationship between the occurrence of these clusters and a vowel deletion process which is both historical and productive (Clark, 1985; Lynch, 2000c; Thieberger, 2006). For the productive process used by contemporary speakers, investigations of corpus data show that short vowels are frequently deleted when they occur in the penultimate syllable of the word, though this is mediated by phonotactic, grammatical, and some lexical and stylistic factors (Billington et al., 2020). These observations raise the question of whether vowel deletion in Nafsan, when it occurs, only occurs in unstressed or weak prosodic contexts, but given that prominence patterns in Nafsan remain under-described, this has not been clearly established.
Previous work on Nafsan includes some impressions of non-contrastive stress, or lexical prominence, but without a consensus on where, or whether, there is consistent stress placement within a word. Suggested patterns include both final stress and initial stress, with some lexically-specified differences (Capell, 1935-1980; Thieberger, 2006), but the previously unclear status of vowel length has posed an additional challenge to identifying prominence patterns. As noted, recent auditory impressionistic analyses within a wider project on the Nafsan sound system suggest possible word-final prominence. This has not yet been examined experimentally beyond preliminary investigations of patterns in disyllabic words, which we build on here with additional data and analyses (Billington et al., 2018). Analyses of Nafsan intonational patterns for words in different utterance and focus contexts suggest that prominence realisation may be sensitive to syntactic and pragmatic factors (Fletcher et al., 2019), and show that there is a need for targeted analyses of the prosodic realisation of Nafsan words in a controlled utterance environment.

In early research on languages of central Vanuatu, Capell notes that "[i]t is the strong stress that has done much to differentiate the Efate dialects from those of the surrounding islands" (Capell, 1935-1980, p. 8), but it is not clear whether this impression is based on the perceived cues to prominence, or more general patterns of prominence assignment. Languages closely related to Nafsan are reported to have various prominence patterns, including penultimate stress in Namakir (Sperlich, 1991, p. 80), antepenultimate stress in Nguna (Schütz, 1969, p. 11), and penultimate weight-sensitive stress in Lelepa (Lacrampe, 2014, pp. 59-60). Capell observes that among languages of Efate and nearby islands, those which have a prevalence of closed syllables word-finally tend to show final prominence (Capell, 1935-1980, pp. 9-10). Similar connections have been made for languages of the Torres and Banks islands of northern Vanuatu (François, 2005, p. 451). In Nafsan, the most common syllable type is $\mathrm{CVC}$, occurring $43 \%$ of the time in one sample (Thieberger, 2006, p. 58), largely due to the frequency of closed syllables word-finally.

\section{Aims of the current study}

There have been various different views regarding prominence patterns in Nafsan, and in order to establish a better understanding of the Nafsan phonological system, there is a need for a more systematic investigation of the prosodic realisation of Nafsan words produced in a consistent utterance context, using an approach which considers the ways this may interact with phonemic vowel length and different word structures. The primary aim of this study is to investigate whether there are phonetic differences in the realisation of vowels depending on word position, on the basis of duration, intensity, fundamental frequency, and formant frequencies, which suggest that vowels in final syllables are more prominent than those in preceding syllables. A secondary aim of the study is to examine whether 
phonemically long and short vowels show similar phonetic characteristics in the same word position, or are treated differently, and to what extent duration correlates with observed prominence patterns. The methodological approach used to address these aims is outlined in Sec. II, followed by results in Sec. III and concluding discussion in Sec. IV.

\section{METHOD}

\section{A. Participants}

The participants in this study were four adult speakers of Nafsan from Erakor village in Efate, Vanuatu: three men (GK, LE, MJ) and one woman (MK). All identify Nafsan as their first language, and the language they use at home. In addition, all speak the English-lexified creole Bislama, GK and LE have knowledge of English and some French, MJ and MK have knowledge of French, and all have a small amount of knowledge of language varieties spoken in other parts of Vanuatu. In Vanuatu, multilingualism of this sort is typical; Bislama is a lingua franca used by Ni-Vanuatu people across the archipelago, and an official language alongside English and French, the languages used in the education system.

\section{B. Materials and procedures}

A set of 77 two- and three-syllable word forms was compiled as stimuli (shown in Appendix A). This was drawn from the Nafsan lexical database maintained by the third author, which currently has $\sim 3800$ entries (see Thieberger (2011b) for an earlier version) and the corpus of $\sim 130$ narratives collected during language documentation work since the late 1990s (see, e.g., Thieberger (2011a)). The words were selected to comprise only $\mathrm{CV}(\mathrm{C})$ structures (no complex onsets), and to contain phonemically long and short vowels in different word positions, to allow investigation of whether the location of long vowels within the word interacts with prominence patterns hypothesised to be related to syllable position within the word. The majority of the vowels in these words were open /a, a:/. The consonantal environment of vowels varied, but adjacent voiceless stops were preferred where possible within the available lexical data. Twosyllable words $(n=46)$ had the structures CV.CVC, CV.CVVC, CVV.CVC, and CVV.CVVC, and three-syllable words $(n=31)$ had the structures CV.CV.CVC, CV.CV.CVVC, CV.CVV.CVC, and CV.CVV.CVvc. Trisyllabic words are less common in Nafsan (disyllabic words are most common in the lexical database, followed by monosyllabic words), and there are therefore fewer lexical items available for inclusion in the stimuli, and not all combinations of syllable types are attested.

The duration values of vowels in final and non-final syllables are not directly comparable in these structures, given that non-final syllables are open and the final syllables are closed, but this combination of word structures is necessary given the frequency with which different phonotactic patterns occur in Nafsan. Though medial CVC syllables are possible, they are less frequent, and word-final $\mathrm{CV}$ syllables are much less common than final CVC syllables. In addition, the characteristics of non-final $\mathrm{CV}$ syllables are of particular interest, given that this is an environment in which vowel deletion occurs. Deletion is not attested for vowels in the word forms included as stimuli, though it is worth noting that it is challenging to compile a set of materials examining short vowels in this environment which are not deleted, given that vowel deletion is both a change that has affected large portions of the lexicon and a process that remains productive in specific morphophonological contexts. However, there are various exceptions to its occurrence, discussed in detail in Billington et al. (2020); while some of these appear to be lexical, the main restrictions are phonotactic and grammatical. Long vowels are never deleted, and short vowels are not deleted where deletion would result in a dispreferred consonant sequence. Short vowels in various grammatical morphemes are also not deleted, most notably in proclitics on verbs, for example, in the dual realis prefix /ra-/ which has been included in a number of items on the wordlist.

Each word was recorded 3 times in a medial frame, following a spoken prompt, with an occasional fourth repetition due to, e.g., coughing or laughter. The frame was komam util __ sernrak "We say ___ usually." Recordings were made in a sheltered area during fieldwork in Erakor, and have been archived with other recordings relating to the wider project on Nafsan phonetic and phonological patterns (Billington, 2017). Data were recorded at an archival sampling rate of $96 \mathrm{kHz}$ and 24-bit depth, using a Zoom (Tokyo, Japan) H6 audio recorder and a Countryman Associates (Menlo Park, CA) H6 headset microphone with a hypercardioid polar pattern, and downsampled to $44.1 \mathrm{kHz} 16$-bit for analysis. Tokens were balanced across participants, but, as shown in Tables I and II, they are not balanced for vowel length category and word structure, given the limitations of available lexical data and the frequency with which different structures occur. The final dataset contained 2269 vowel tokens drawn from 942 utterances produced. All were included in analyses, though it is worth noting that nine utterances with trisyllabic target words were produced with audibly different prosodic patterns which may relate to pause phenomena and differing overall intonation. ${ }^{2}$ Among data for disyllabic words, $91 \%$ of vowel tokens were open vowels (/a, a:/), and among data for trisyllabic words, $74 \%$ were open vowels.

TABLE I. Number of vowel tokens from disyllabic words, by word shape and vowel length.

\begin{tabular}{lcccccc}
\hline \hline & & \multicolumn{2}{c}{ syll 1} & & \multicolumn{2}{c}{ syll 2} \\
\cline { 3 - 4 } \cline { 5 - 6 } Word shape & No. of words & /V/ & N:/ & & /V/ & /V:/ \\
\hline CV.CVC & 19 & 229 & - & 229 & - \\
CV.CVVC & 10 & 125 & - & - & 125 \\
CVV.CVC & 11 & - & 128 & 128 & - \\
CVV.CVVC & 6 & - & 75 & - & 75 \\
total tokens & & $\mathbf{3 5 4}$ & $\mathbf{2 0 3}$ & $\mathbf{3 5 7}$ & $\mathbf{2 0 0}$ \\
\hline \hline
\end{tabular}


TABLE II. Number of vowel tokens from trisyllabic words, by word shape and vowel length.

\begin{tabular}{|c|c|c|c|c|c|c|c|}
\hline \multirow[b]{2}{*}{ Word shape } & \multirow[b]{2}{*}{ No. of words } & \multicolumn{2}{|c|}{ syll 1} & \multicolumn{2}{|c|}{ syll 2} & \multicolumn{2}{|c|}{ syll 3} \\
\hline & & /V/ & /V:/ & /V/ & /V:/ & /V/ & /V:/ \\
\hline CV.CV.CVC & 11 & 135 & - & 135 & - & 135 & - \\
\hline CV.CV.CVVC & 9 & 122 & - & 122 & - & - & 122 \\
\hline CV.CVV.CVC & 9 & 102 & - & - & 102 & 102 & - \\
\hline CV.CVV.CVVC & 2 & 26 & - & - & 26 & - & 26 \\
\hline total tokens & & 385 & $\mathbf{0}$ & 257 & 128 & 237 & 148 \\
\hline
\end{tabular}

\section{Data processing and analysis}

Utterances were transcribed orthographically in Praat (Boersma and Weenink, 2018), and orthographic transcriptions were converted to phonemic transcriptions in the Speech Assessment Methods Phonetic Alphabet. Using the TextGrid files and associated WAV files, automatic segmentation of the speech signal was performed via the web interface of the Munich Automatic Segmentation System (Kisler et al., 2017), using the language-independent model for segment identification. Segment boundaries in the output TextGrid files were checked and manually corrected where necessary with reference to wideband spectrograms and corresponding waveforms in Praat. A hierarchical database was constructed using the EMU Speech Database Management System (Winkelmann et al., 2017), including tiers for the phonemic segments, syllables, and words. The acoustic and durational characteristics of vowel tokens produced in the target words were queried and analysed using the emuR package in R (R Core Team, 2018; Winkelmann et al., 2018).

Measures of interest in this study are vowel duration (in $\mathrm{ms}$ ), intensity [root-mean-square (RMS) amplitude, in dB], fundamental frequency (in $\mathrm{Hz}$ ), and first and second formant frequencies (in $\mathrm{Hz}$ ). Reported intensity measures are relative, based on values at vowel midpoints in comparison to the values at the midpoint of the coda lateral in the word preceding the target word. For fundamental frequency $(f 0)$, measures were taken at regular $5 \%$ intervals from $5 \%$ of the way into the vowel to $95 \%$ of the way into the vowel, allowing for trajectories of 19 points. Any points with zero values, largely due to breathiness, devoicing, or creakiness, were removed, resulting in 19165 observations for vowels in disyllabic words and 20200 observations for vowels in trisyllabic words. Statistical comparisons are based on $f 0$ values at $25 \%, 50 \%$, and $75 \%$. For first formant $(F 1)$ and second formant $(F 2)$ frequency, measures were similarly taken at regular 5\% intervals for a subset of the data containing only open vowels /a, a:/, which as noted comprised the majority of the data (1865 tokens). After removal of zero values this resulted in 19180 observations for $F 1$ and 19212 observations for $F 2$ for open vowels in disyllabic words, and 15987 observations for $F 1$ and 16178 observations for $F 2$ for open vowels in trisyllabic words. Statistical comparisons for $F 1$ and $F 2$ are based on values at vowel midpoints.
Data relating to the different measures were tested with linear mixed-effects models using the 1 me 4 package (Bates et al., 2015) in R. Model selection was undertaken using the step function of the lmerTest package (Kuznetsova et al., 2017). Fixed effects included in the initial full models were: syllable position (in word), phonemic vowel length, preceding place, manner and voicing of consonant, following place, manner and voicing of consonant, and vowel quality; random effects included speaker, word, word shape, and syllable shape. The fixed effects used in final models for each measure were those identified via step as comprising the best fitting model, and these are the effects reported for each comparison in Sec. III (and in full results in Appendixes B and C). All models also included random intercepts for speaker and word and by-speaker random slopes for word, apart from models for $f 0$ in disyllabic words (for which only random intercepts were retained in the output). In each case, model significance was also confirmed via a likelihood ratio test. Post hoc analyses were undertaken using Bonferroni-adjusted $p$-values. Results with $p$ values $<0.05$ are considered significant. Given that the primary research question relates to word-internal patterns, and given the different nature of the datasets for disyllabic and trisyllabic words, patterns for disyllabic and trisyllabic words are examined separately. Given that there was only one female participant among the four participants in this study, potential differences in $f 0$ patterns due to differing pitch ranges are considered on the basis of individual speakers rather than according to gender; selected results are reported in semitones for each participant, and plots showing $f 0$ as well as duration are based on values normalised across speakers using the Lobanov method.

\section{RESULTS}

\section{A. Duration}

Duration values for vowels in disyllabic words, shown in Fig. 1, clearly illustrate the vowel length distinction in Nafsan, as expected given that this has been recently established. The effect of vowel length category on vowel duration is significant $[F(1,685)=1566, p<0.001]$, and post hoc tests show that long vowels are an estimated $62 \pm 2 \mathrm{~ms}$ longer than short vowels in disyllabic words $(p<0.001)$. The effect of syllable position is also significant $[F(1,554)$ $=11.89, p<0.001$ ], with vowels in final syllables showing a small but significant increase in duration of an estimated $5 \pm 1 \mathrm{~ms}$ compared to those in initial syllables $(p<0.001)$. There is also a significant interaction between syllable position and vowel length $[F(1,525)=6.93, p<0.01]$. Post hoc analyses shown that phonemically short and long vowels exhibit significant and sizeable duration differences in all comparisons: long vowels in both initial and final syllables have higher duration values than short vowels in initial syllables by an estimated $67 \pm 2-3 \mathrm{~ms}(p<0.001)$, and higher duration values than short vowels in final syllables by an estimated $57 \pm 2 \mathrm{~ms}(p<0.001)$. There are no significant differences between phonemically long vowels occurring in 


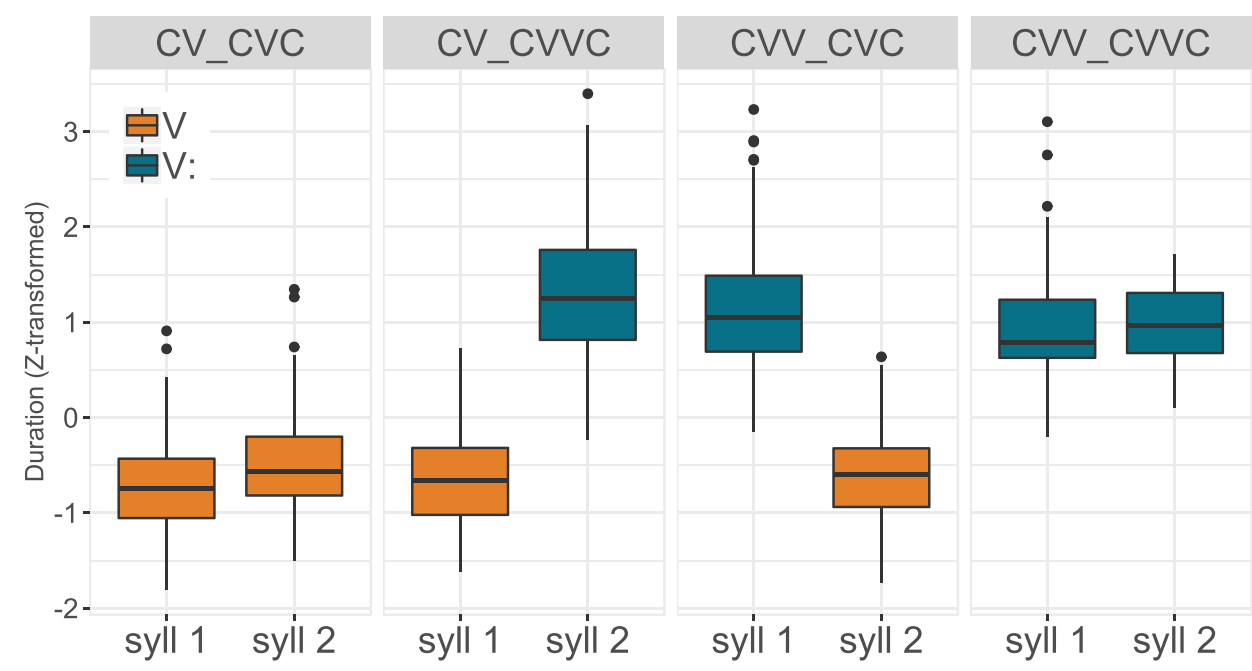

FIG. 1. (Color online) Duration (Lobanov-normalised) of short and long vowels in initial and final syllables of disyllabic Nafsan words (by word structure). initial compared to final syllables $(p=1)$, but short vowels in final syllables are an estimated $9 \pm 2 \mathrm{~ms}$ longer than short vowels in initial syllables $(p<0.001)$. Though larger differences may be observed for vowels of the same quantity in initial and final syllables in data with open rather than closed final syllables, the distributions shown here suggest that any duration differences correlating with word position are much smaller than those correlating with phonemic length. Some minor effects of the manner and voicing of the preceding consonant and the place and voicing of the following consonant are also observed (see Appendix B).

Similar patterns are observed for vowels in trisyllabic words, with the distributions of duration values, shown in Fig. 2, also patterning according to phonemic vowel length. The effect of vowel length on duration is significant $[F(1,949)=2400.28, p<0.001]$, and long vowels are an estimated $68 \pm 1 \mathrm{~ms}$ longer than short vowels in trisyllabic words $(p<0.001)$. The effect of syllable position is also significant $[F(2,974)=6.59, p<0.01]$; while there are no duration differences between vowels in initial and medial syllables $(p=0.73)$, vowels in final syllables show small but significant differences, and are an estimated $6 \pm 2 \mathrm{~ms}$ longer than vowels in initial syllables $(p<0.01)$, and $4 \pm 1 \mathrm{~ms}$ longer than vowels in medial syllables $(p<0.01)$. There was no interaction between syllable position and vowel length for vowel duration in trisyllabic words, but there were some minor effects of the place and manner of the preceding and following consonant (see Appendix C). As can be seen in Table III, long vowels in this dataset are overall approximately twice as long as short vowels in corresponding word positions.

\section{B. Intensity}

Relative intensity patterns for vowels, based on the difference in RMS amplitude between the vowel midpoint and the midpoint of the lateral coda in the preceding word, are shown in Fig. 3 for disyllabic words. The effect of syllable position is significant $[F(1,1003)=4.30, p<0.05]$, but the observed difference is very small; vowels in final syllables have an increase in intensity that is an estimated $0.5 \pm 0.2 \mathrm{~dB}$ greater than that for vowels in initial syllables $(p<0.05)$. Phonemic vowel length also has a significant effect on relative intensity $[F(1,1106)=67.79, p<0.001]$, such that long vowels have relative intensity values an estimated $2.2 \pm 0.3 \mathrm{~dB}$ higher than for short vowels $(p<0.001)$. As for duration values in disyllabic words, there is also an

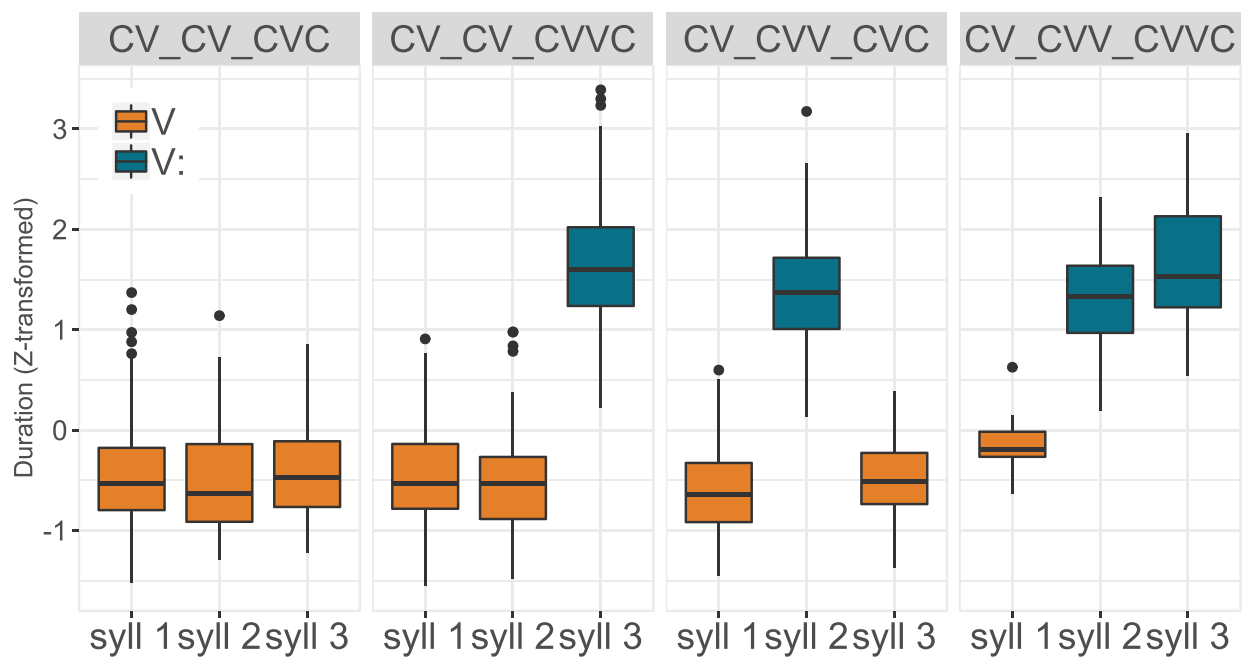

FIG. 2. (Color online) Duration (Lobanov-normalised) of short and long vowels in initial, medial, and final syllables of trisyllabic Nafsan words (by word structure). 
TABLE III. Mean duration of short compared to long vowels in different word positions.

\begin{tabular}{lcccc}
\hline \hline & & syll 1 & syll 2 & syll 3 \\
\hline Disyllables & /V/ & $61 \mathrm{~ms}$ & $66 \mathrm{~ms}$ & \\
& /V:/ & $126 \mathrm{~ms}$ & $134 \mathrm{~ms}$ & \\
& ratio /V/:/V:/ & $1: 2.07$ & $1: 2.03$ & \\
Trisyllables & $/ \mathrm{V} /$ & $60 \mathrm{~ms}$ & $58 \mathrm{~ms}$ & $62 \mathrm{~ms}$ \\
& $/ \mathrm{V}: /$ & - & $124 \mathrm{~ms}$ & $131 \mathrm{~ms}$ \\
& ratio /V/:/V:/ & & $1: 2.14$ & $1: 2.11$ \\
\hline \hline
\end{tabular}

interaction between syllable position and vowel length. Long vowels in both initial and final syllables have higher relative intensity values by an estimated $2.7-2.8 \pm 0.4 \mathrm{~dB}$ compared to short vowels in initial syllables $(p<0.001)$, and by an estimated 1.6-1.7 $\pm 0.3-0.4 \mathrm{~dB}$ compared to short vowels in final syllables $(p<0.001)$. There are no significant differences in relative intensity for long vowels occurring in initial compared to final syllables $(p=1)$, but intensity values for short vowels in final syllables differ from those for short vowels in initial syllables, with intensity values an estimated $1 \pm 0.3 \mathrm{~dB}$ higher $(p<0.01)$. As for duration, then, differences on the basis of RMS amplitude in disyllabic words are associated more with phonemic vowel length than syllable position. There is also a significant effect of the voicing of the following consonant $[F(1,1098)$ $=10.12, p<0.01]$, with intensity values being slightly lower, by $0.9 \pm 0.3 \mathrm{~dB}$, when the following consonant is voiceless $(p<0.01)$.

Relative intensity values for vowels in trisyllabic words, shown in Fig. 4, exhibit some similar patterns. In this case, syllable position was not retained as a fixed effect during modeling, as it did not have an effect on relative intensity. There is a significant effect of vowel length $[F(1,1140)$ $=33.38, p<0.001]$, with relative intensity values for long vowels an estimated $1.5 \pm 0.3 \mathrm{~dB}$ higher than those for short vowels $(p<0.001)$. There is also a significant effect of the manner of the following consonant $[F(3,1099)=14.28$, $p<0.001$, with lower intensity values observed when the following consonant is an approximant or nasal compared to a fricative or stop (see Appendix C).

\section{Fundamental frequency}

Smoothed $f 0$ trajectories (based on a generalised additive model smoothing function) for vowels in disyllabic words are shown in Fig. 5, and a consistent pattern can be seen across the four word structures. The effect of syllable position is significant for $f 0$ values at $25 \%, 50 \%$, and $75 \%$ points $[F(1,944)=266.30, p<0.001 ; F(1,953)=348.56$, $p<0.001 ; F(1,953)=307.06, p<0.001]$. Post hoc tests confirm that there are significantly higher $f 0$ values in final compared to initial syllables overall, of an estimated $13-15 \pm 1 \mathrm{~Hz}(p<0.001)$. The effect of vowel length is only significant for measures at the $75 \%$ point $[F(1,404)$ $=8.88, p<0.01]$, with $f 0$ values for long vowels an estimated $3 \pm 1 \mathrm{~Hz}$ higher than $f 0$ values for short vowels $(p<0.01)$. As can be seen in Fig. 5, the smoothed trajectories for long vowels in final syllables of disyllabic words show a shallow peak in the later part of the vowel, while for short vowels this rise is absent. For measures at the $25 \%$ point, there are also significant effects of the place and manner of the following consonant $[F(3,798)=3.79, p<0.05$; $F(3,824)=3.96, p<0.01$ ], but few significant differences between pairs in post hoc analyses (see Appendix B).

The $f 0$ trajectories for vowels in trisyllabic words are shown in Fig. 6, and as for disyllabic words, there is an observable pattern of higher $f 0$ values for vowels in final syllables. The effect of syllable position is again significant for $f 0$ values at $25 \%, 50 \%$, and $75 \%$ points $[F(2,959)=226.50$, $p<0.001 ; F(2,960)=228.49, p<0.001 ; F(2,963)=218.03$, $p<0.001]$. There are small but significant differences in $f 0$ values between initial and medial syllables at the $50 \%$ and $75 \%$ points, with values an estimated $3 \pm 1 \mathrm{~Hz}$ higher in medial syllables $(p<0.05)$, but larger differences are observed when comparing final syllables with medial and initial syllables. $F 0$ values in final syllables are an estimated $16-18 \pm 1 \mathrm{~Hz}$ higher than those in medial syllables $(p<0.001)$, and an estimated $18-21 \pm 1 \mathrm{~Hz}$ higher than those in initial syllables $(p<0.001)$. The magnitude of these

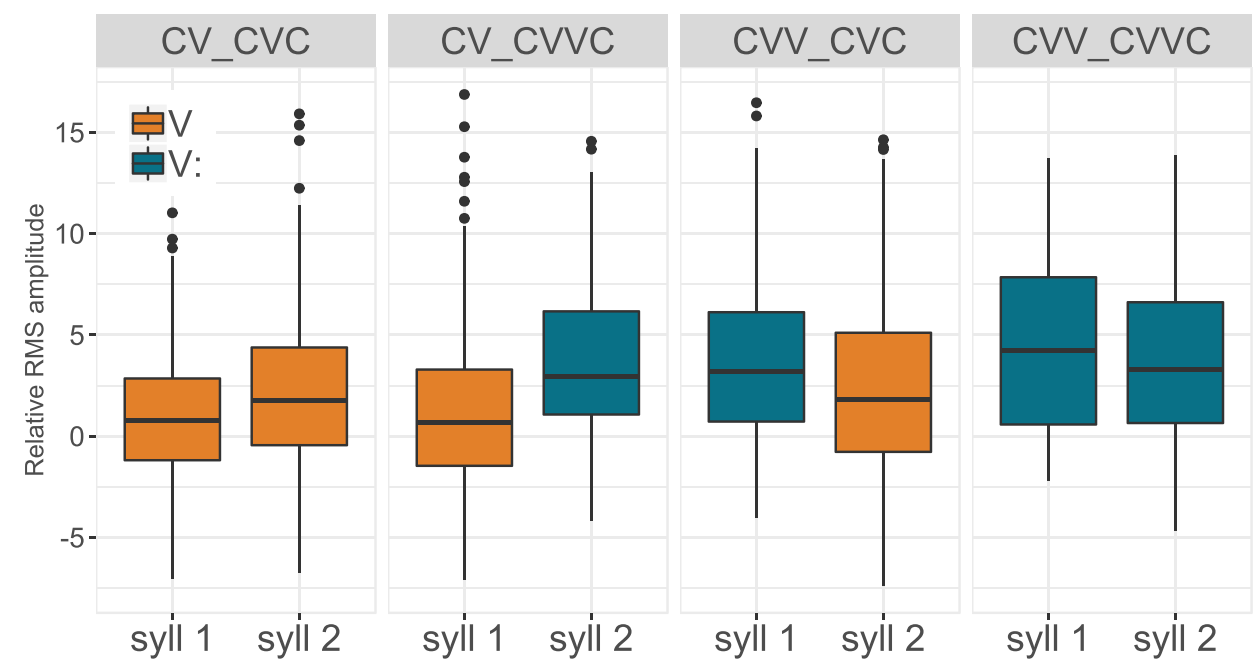

FIG. 3. (Color online) RMS amplitude at midpoints of short and long vowels (relative to midpoints of lateral coda in preceding word) in initial and final syllables of disyllabic Nafsan words (by word structure). 


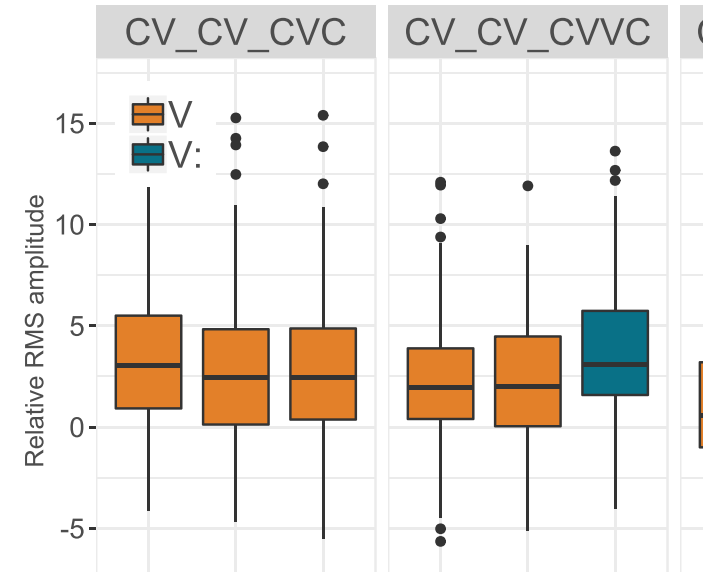

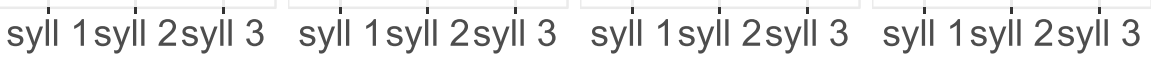

FIG. 4. (Color online) RMS amplitude at midpoints of short and long vowels (relative to midpoints of lateral coda in preceding word) in initial, medial, and final syllables of trisyllabic Nafsan words (by word structure). differences is comparable to that observed between final and initial syllables in disyllabic words. There is also a significant effect of vowel length at all three measurement points $[F(1,1043)=28.17, p<0.001 ; \quad F(1,1046)=20.34$, $p<0.001 ; F(1,1043)=11.95, p<0.001]$, with $f 0$ values an estimated $4-5 \pm 1 \mathrm{~Hz}$ higher for long vowels compared to short vowels. No other segmental effects on $f 0$ values for vowels in trisyllabic words are observed apart from an effect of the voicing of the preceding consonant for values at the $25 \%$ point $[F(1,931)=8.39, p<0.01]$, with $f 0$ values being slightly higher, by an estimated $3 \pm 1 \mathrm{~Hz}$, following a voiceless consonant $(p<0.01)$.

$F 0$ differences in $\mathrm{Hz}$ were also converted to semitones for individual participants, calculated as 12 times log base 2 of each participant's mean $f 0$ at the measurement point of interest, e.g., the $25 \%$ point in an initial syllable, divided by

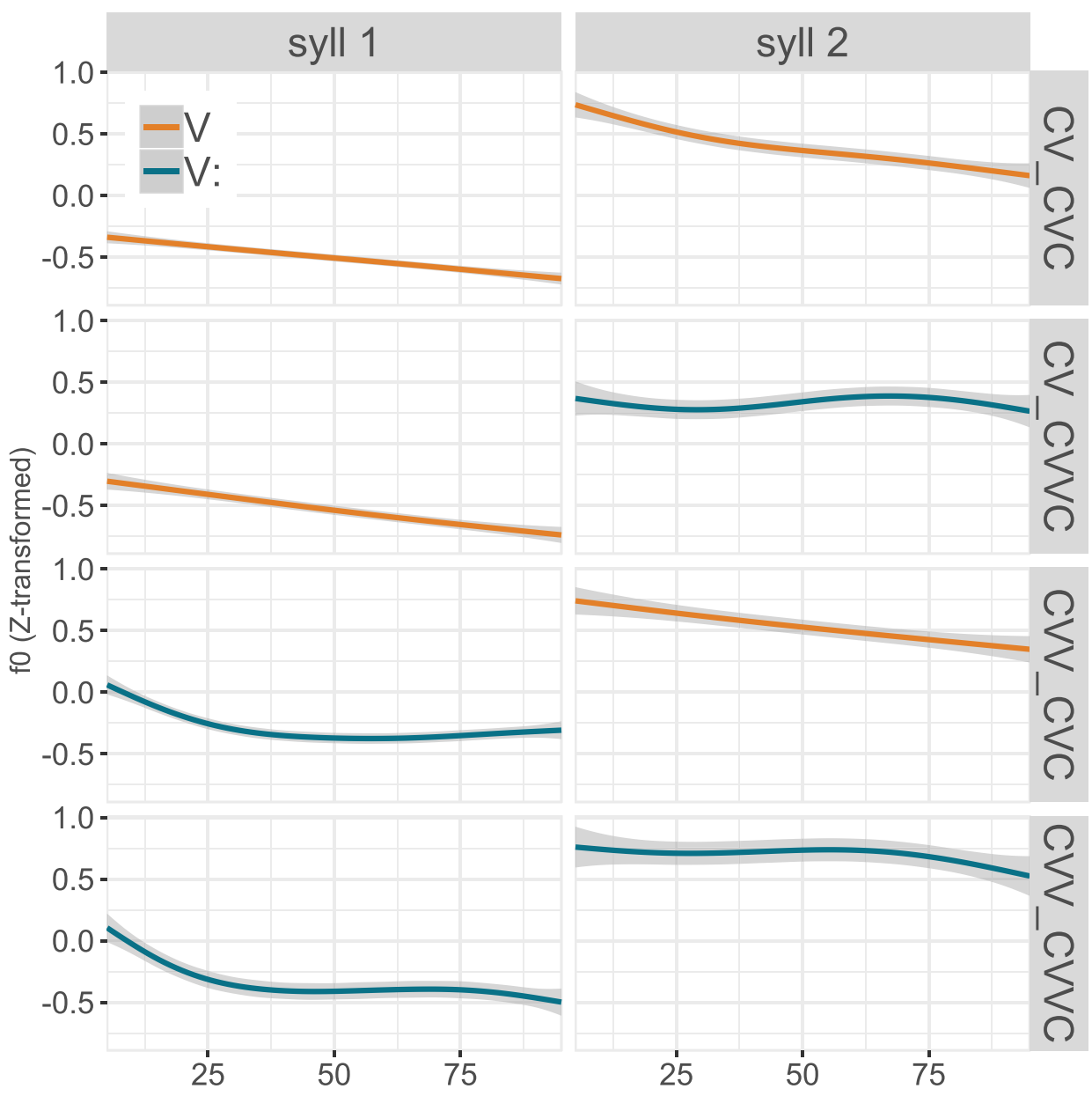

FIG. 5. (Color online) Smoothed fundamental frequency trajectories based on 19 points (Lobanov-normalised) between $0.5 \%$ and $0.95 \%$ of short and long vowels in initial and final syllables of disyllabic Nafsan words (by word structure). 


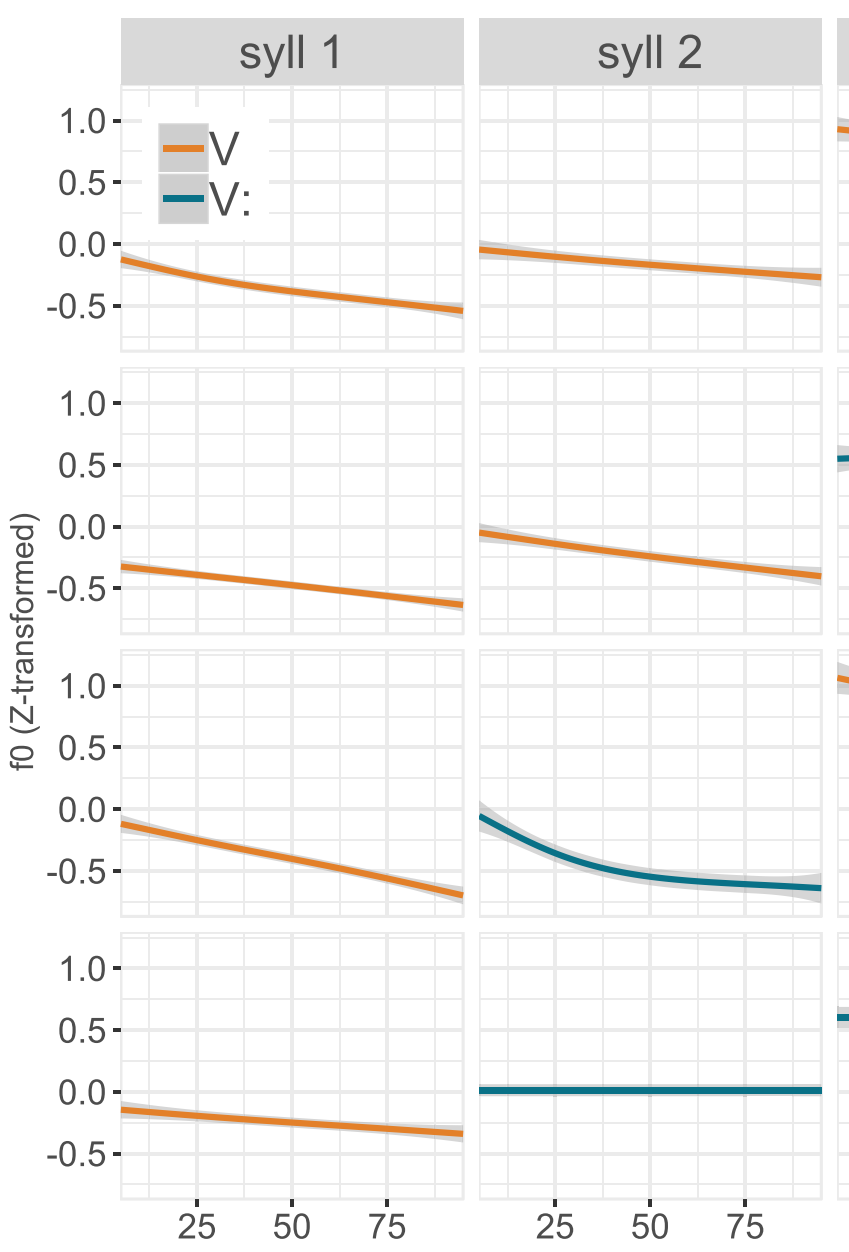

their mean $f 0$ at a comparison point, such as the $25 \%$ point in a final syllable. These are given in Table IV, and show some of the differences between individual participants. Across the four participants, differences between the final and initial syllables of disyllabic words range from 0.72 to 3.01 semitones. For trisyllabic words, differences between final and medial syllables range from 0.62 to 3.15 semitones, and differences between final and initial syllables range from 0.98 to 3.12 semitones.

TABLE IV. Mean differences (in semitones) between final and preceding syllables in disyllabic and trisyllabic words, for each participant.

\begin{tabular}{lcccc}
\hline \hline Participant & Point & $\begin{array}{c}\text { Disyllables } \\
\text { syll2 }>\text { syll1 }\end{array}$ & $\begin{array}{c}\text { Trisyllables } \\
\text { syll3 }>\text { syll2 }\end{array}$ & syll3 > syll1 \\
\hline GK & $25 \%$ & 0.80 & 0.64 & 1.07 \\
& $50 \%$ & 0.74 & 0.64 & 1.01 \\
& $75 \%$ & 0.72 & 0.62 & 0.98 \\
LE & $25 \%$ & 1.37 & 1.60 & 1.90 \\
& $50 \%$ & 1.19 & 1.37 & 1.74 \\
& $75 \%$ & 0.90 & 1.08 & 1.53 \\
MJ & $25 \%$ & 1.46 & 1.89 & 1.89 \\
& $50 \%$ & 1.85 & 2.15 & 2.14 \\
& $75 \%$ & 1.99 & 2.49 & 2.54 \\
MK & $25 \%$ & 1.96 & 2.43 & 2.22 \\
& $50 \%$ & 2.55 & 2.72 & 2.58 \\
& $75 \%$ & 3.01 & 3.15 & 3.12 \\
\hline \hline
\end{tabular}

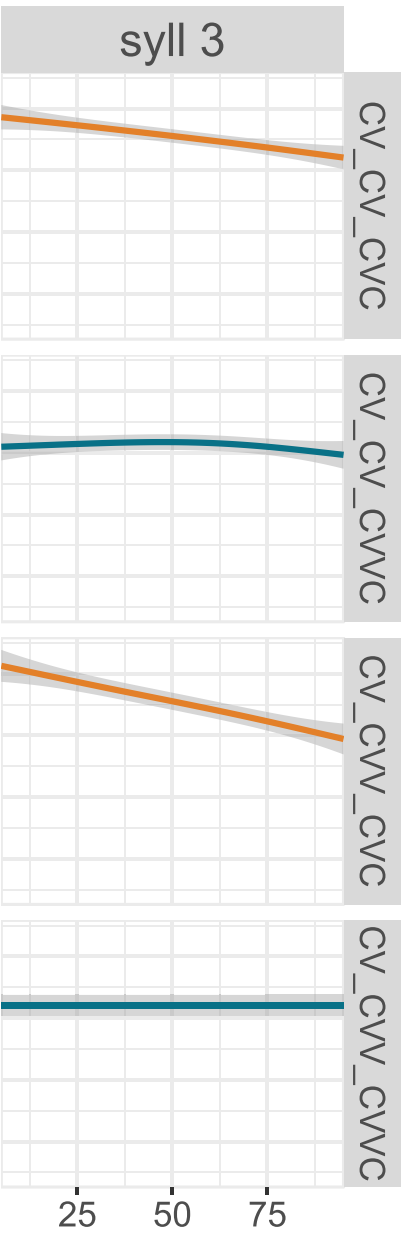

FIG. 6. (Color online) Smoothed fundamental frequency trajectories based on 19 points (Lobanov-normalised) between $0.5 \%$ and $0.95 \%$ of short and long vowels in initial, medial, and final syllables of trisyllabic Nafsan words (by word structure).

\section{First and second formant frequency}

Smoothed trajectories of $F 1$ and $F 2$ frequencies for open vowels /a, a:/ in disyllabic words are shown in Fig. 7. For $F 1$ values taken at vowel midpoints, the effect of syllable position is significant $[F(1,626)=96.18, p<0.001] . F 1$ values are an estimated $61 \pm 6 \mathrm{~Hz}$ lower for open vowels in initial syllables compared to final syllables $(p<0.001)$. There is no overall effect of syllable position on $F 2$ values

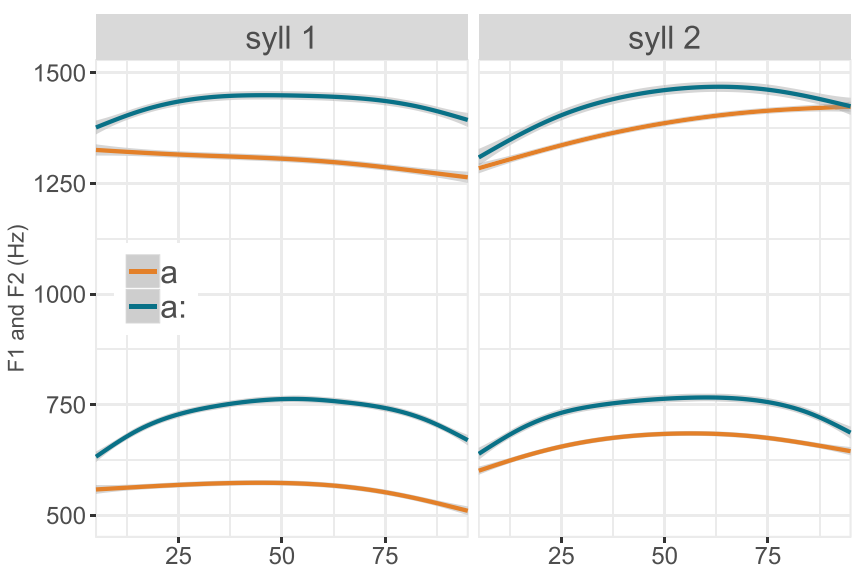

FIG. 7. (Color online) Smoothed first and second formant frequency trajectories based on 19 points between $0.5 \%$ and $0.95 \%$ of short and long open vowels in initial and final syllables of disyllabic Nafsan words. 
at midpoints of open vowels. There is a significant effect of vowel length on both $F 1[F(1,594)=527.24, p<0.001]$ and $F 2[F(1,637)=57.45, p<0.001]$, with $F 1$ values an estimated $151 \pm 7 \mathrm{~Hz}$ lower for /a/ compared to /as/ $(p<0.001)$, and $F 2$ values an estimated $80 \pm 11 \mathrm{~Hz}$ lower $(p<0.001)$. For $F 1$, there is also a significant interaction between vowel length and syllable position $[F(1,306)$ $=75.57, p<0.001]$. The results of post hoc tests show that, as can be seen in Fig. 7, F1 values for short /a/ in initial syllables are substantially lower than for long /a:/ in both initial and final syllables, by an estimated $217-219 \pm 14 \mathrm{~Hz}(p<0.001)$. $F 1$ values for short /a/ in final syllables are also lower than for long /a:/ in initial and final syllables, with a smaller estimated difference of $86-88 \pm 10 \mathrm{~Hz}(p<0.001)$. As also observed for duration and relative intensity in disyllabic words, there are no significant $F 1$ differences between long vowels in initial compared to final syllables $(p=1)$, but there are differences between short vowels in initial compared to final syllables. In this case, the estimated difference is reasonably large, with $F 1$ values $131 \pm 12 \mathrm{~Hz}$ lower for /a/ occurring in initial syllables $(p<0.001)$. For $F 1$, there is also an effect of the place of articulation of the preceding consonant, and for $F 2$, there are effects of the place and manner of the consonant both preceding and following the vowel, shown in Appendix B.

For trisyllabic words, trajectories of $F 1$ and $F 2$ frequencies for /a, a:/ are shown in Fig. 8. There is a significant effect of vowel length on both $F 1[F(1,737)=182.17$, $p<0.001]$ and $F 2[F(1,628)=47.06, p<0.001]$. As for disyllabic words, short vowels have lower values than long vowels, by an estimated $98 \pm 7 \mathrm{~Hz}$ for $F 1(p<0.001)$ and $73 \pm 11 \mathrm{~Hz}$ for $F 2(p<0.001)$. There is also a significant interaction between vowel length and syllable position in both cases $[F(3,549)=18.05, p<0.001 ; F(3,419)=4.61$, $p<0.01]$. Comparing values for $/ \mathrm{a} /$ and $/ \mathrm{a} / \mathrm{/}$ in final syllables, there is a small but significant difference in $F 1$, with /a/ having values an estimated $35 \pm 12 \mathrm{~Hz}$ lower than those for $/ \mathrm{a}: /(p<0.05)$. There are no significant $F 2$ differences between /a/ and /a:/ in final syllables $(p=0.80)$. In medial syllables, however, the largest differences in vowel quality are observed, with $F 1$ values for /a/ an estimated $169 \pm 13 \mathrm{~Hz}$ lower than for $/ \mathrm{a} / /(p<0.001)$, and $F 2$ values an estimated $121 \pm 19 \mathrm{~Hz}$ lower $(p<0.001)$. There are also significant differences in both $F 1$ and $F 2$ between short /a/ and long /a:/ occurring in different syllable positions, as shown in Appendix C.

While for disyllabic words there were no $F 1$ differences between long /a:/ in penultimate compared to final syllables, in trisyllabic words $F 1$ values for /a:/ are somewhat higher in penultimate syllables than final syllables, by an estimated $59 \pm 13 \mathrm{~Hz}(p<0.001)$, though there are no significant differences in $F 2(p=0.58)$. For short vowels, patterns in penultimate compared to final syllables are similar to results for disyllabic words in that $F 1$ values are an estimated $90 \pm 13 \mathrm{~Hz}$ lower for /a/ occurring in penultimate syllables $(p<0.001)$, and additionally $F 2$ values are an estimated $67 \pm 19 \mathrm{~Hz}$ lower $(p<0.01)$. Furthermore, $F 1$ values for short /a/ are lower in penultimate compared to initial syllables, by an estimated $63 \pm 10 \mathrm{~Hz}(p<0.001)$. As for disyllabic words, effects of the place and manner of the preceding and following consonant are also observed for measures of F2 (Appendix C).

\section{DISCUSSION AND CONCLUSIONS}

These findings for disyllabic and trisyllabic Nafsan words provide compelling evidence that Nafsan words tend to be produced with greater prominence at the right edge. The clear pattern of higher $f 0$ values in final compared to preceding syllables suggests that $f 0$ likely plays an important role in prominence marking. Across the data, vowels in final syllables have $f 0$ values ranging from 13 to $21 \mathrm{~Hz}$ higher than those in preceding syllables. In semitones, these differences range from 0.62 to 3.15 , and are likely perceptible in

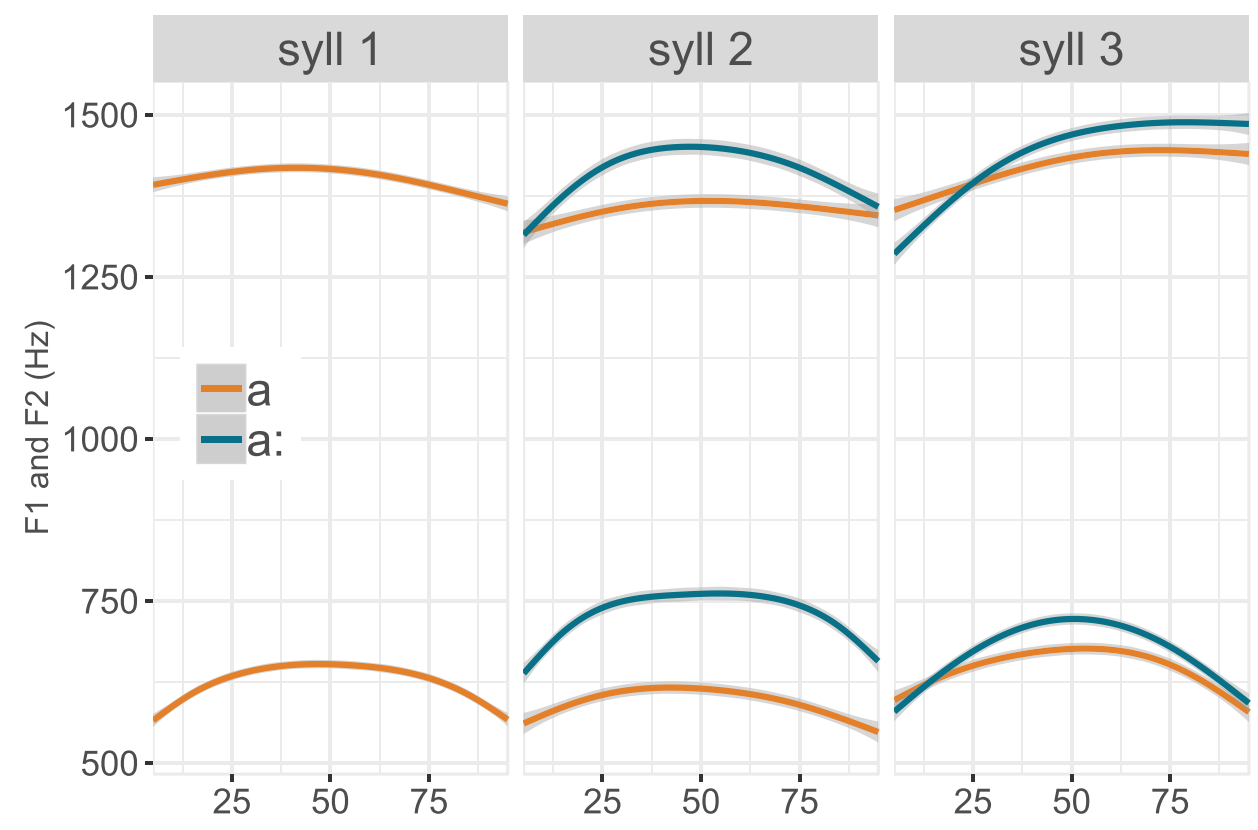

FIG. 8. (Color online) Smoothed first and second formant frequency trajectories based on 19 points between $0.5 \%$ and $0.95 \%$ of short and long open vowels in initial, medial, and final syllables of disyllabic Nafsan words. 
most cases, though the extent to which speakers of Nafsan are attentive to $f 0$ cues requires perceptual investigation. There are also some small effects of vowel length, with slightly higher $f 0$ values observed for long vowels in some comparisons. The trajectories for long vowels in at least disyllabic words also suggest possible $f 0$ timing differences between long and short vowels in prominent syllables, which will be an interesting topic to explore in future studies focusing on prominence realisation. There are no indications, on the basis of $f 0$ or other measures, that initial syllables are prominent in this controlled data, nor that the location of prominence is influenced by the location of long vowels within the word, as noted for some other languages in Vanuatu (Crowley, 2006).

Results for $F 1$ and $F 2$ at midpoints of open vowels /a, a:/ offer supporting evidence for right-edge prominence, and show that phonemic vowel length is an important factor to consider for spectral measures in different syllable positions in Nafsan. While some F2 differences are reported between vowels in different positions and of different lengths, differences in $F 1$ are the most notable. In examining the interactions between syllable position and vowel length for $F 1$ values, there are significant differences in all pairwise comparisons apart from between long vowels in initial compared to final syllables in disyllabic words, but the magnitudes of these estimated differences are of interest. $F 1$ differences between short and long vowels in final syllables are $35-86 \mathrm{~Hz}$, much smaller than the $F 1$ differences of $169-219 \mathrm{~Hz}$ between short and long vowels in penultimate syllables. Short vowels in penultimate syllables also have lower $F 1$ values than short vowels in final syllables, by $75-131 \mathrm{~Hz}$, and, in data for trisyllabic words, $F 1$ values $49 \mathrm{~Hz}$ lower than in initial syllables. Taken together, these patterns are indicative of centralisation of short vowels in syllables preceding those with high $f 0$ values. This is of particular interest given that short vowels in CV syllables are the site of productive vowel deletion when it takes place (Billington et al., 2020). Penultimate short vowels in this dataset occur in words which constitute exceptions to the widespread deletion process, but these vowels still show evidence of reduction, suggesting that this is a prosodically weak context in comparison to the word-final syllable context. Differences in vowel space peripherality for long vowels and their short counterparts across vowel qualities are currently under investigation in Nafsan, but indications are that the differences observed for $/ \mathrm{a} /, \mathrm{a} / \mathrm{i} /$ in penultimate syllables in this data are much larger than the general tendency for short vowels to be only slightly less peripheral in monosyllabic words of different syllable types. The realisation of vowels of different qualities in different word positions and phonotactic structures will be a particularly interesting area for further research.

Duration and intensity are likely only minor cues to prominence, with significant differences on the basis of syllable position being very small. Instead, duration, and to a lesser extent intensity, appear to be robust correlates of vowel length and bolster recent evidence for the status of quantity distinctions in Nafsan. Phonemically long vowels show reliably and substantially greater duration values than short vowels in different contexts, of 62-68 ms. Overall, phonemically long vowels are twice as long as short vowels in this dataset, as also observed across all five vowel qualities in monosyllabic Nafsan words (Billington et al., 2020). Across word positions, phonemically long vowels also show higher intensity values, as indicated by relative RMS amplitude at vowel midpoints, though the differences of 1.5-2.2 $\mathrm{dB}$ are not large. This is not unlike findings for correlates of lexical stress in some other languages with phonemic vowel length, such as Hungarian (Vogel et al., 2016). While there may be larger duration differences correlating with word position in data where the final as well as initial and medial syllables are all either open or closed, it appears that in Nafsan, duration differences correlating with vowel length are likely to be wellpreserved regardless of syllable prominence. Similar observations have been made based on exploratory duration measures for vowels in the closely-related language Lelepa (Lacrampe, 2014).

The results presented here accord with impressions of final prominence in Nafsan reported in some sources (Capell, 1935-1980), and in pointing towards the importance of $f 0$ as a major correlate, also suggest the possibility that the acoustic patterns of prominence marking in Nafsan are similar to languages such as Japanese which have traditionally been described as having a non-stress accent (Beckman, 1986). However, given that other ongoing research on Nafsan indicates that strong rising $f 0$ movements at the right edge of a word may in fact demarcate the right edge of an accentual phrase (Fletcher et al., 2019), it will also be worth considering whether the language has a prosodic system like that of Korean or French (e.g., Jun (1998); Jun and Fougeron (2002)), with high tone targets at right edges relating to constituents that are not necessarily lexical but phrasal. This relatively controlled data included a small number of exceptions to the overall pattern of right-edge prominence, in some cases perhaps due to pause phenomena that resulted in the tokens being produced at the beginning of intonational phrases, which would also support an analysis of phrasal rather than lexical prominence in Nafsan, although this requires further investigation. As noted in Sec. IA, in some grammatical descriptions of languages of Vanuatu for which no clear pattern of lexical prominence was observable, such as Daakaka (von Prince, 2015) and Nahavaq (Dimock, 2009), phrasal prominence has also been suggested, though has not yet been the subject of targeted explorations. The present results for vowels produced in an utterance-medial frame controlling for word length and syllable structure will provide a useful point of reference in ongoing work on Nafsan with more participants, which includes comparisons of the phonetic characteristics of Nafsan words of different lengths and syllable structures in utteranceinitial, utterance-medial, and utterance-final contexts and under different focus conditions.

Oceanic languages are under-represented in experimental prosodic research, and as crosslinguistic overviews show, 
there is much that remains to be understood regarding the range of prominence patterns, and phonetic cues to prominence, within this language family (Himmelmann and Kaufman, 2020; Lynch, 2000b). The Southern Oceanic languages of Vanuatu are especially well-suited to investigations of the different ways that segmental and prosodic phenomena interact, given that they show enormous diversity in their sound systems. These results show that in addition to furthering the phonetically-based description of individual languages, more detailed understandings of languageinternal prosodic patterns in Oceanic languages may offer insights into the phonetic mechanisms underpinning phonological processes, while also contributing to a better understanding of the typological profile of these languages.

\section{ACKNOWLEDGMENTS}

Sincere thanks to all the Nafsan speakers who have participated in and facilitated this and earlier work, in particular Gray Kaltap̃au, Lionel Emil, Michael Joseph, and Marinette Kalpram for their involvement in this study, and Lingkary Kalpram and Yvanna Ataurua for their assistance during fieldwork in Erakor. This research was conducted with support from the ARC Centre of Excellence for the Dynamics of Language (Project ID No. CE140100041).

\section{APPENDIX A}

TABLE V. List of disyllabic and trisyllabic Nafsan words used in materials for this study $(\mathrm{SG}=\mathrm{singular} ; \mathrm{DL}=\mathrm{dual} ; \mathrm{PL}=\mathrm{plural} ; \mathrm{RS}=\mathrm{realis} ; \mathrm{DP}=\mathrm{direct}$ possession).

\begin{tabular}{|c|c|c|c|c|c|}
\hline Word shape & IPA & Gloss & Word shape & IPA & Gloss \\
\hline CV.CVC & rakat & "bite DL RS" & CVV.CVVC & ta:kpair & "sin" \\
\hline CV.CVC & rapak & "go towards DL RS" & CVV.CVVC & ta:kpo:s & "be curved" \\
\hline CV.CVC & ratap & "be taboo DL Rs" & CVV.CVVC & ta:lo:f & "shake hands" \\
\hline CV.CVC & ratak & "husk coconut DL Rs" & CVV.CVVC & te:ymo:l & "animal" \\
\hline CV.CVC & rakpas & “chase DL RS" & CVV.CVVC & warlo:p & "crab sp." \\
\hline CV.CVC & ralat & “cut DL RS” & CVV.CVVC & parri:k & "after a while" \\
\hline CV.CVC & rasak & "ascend DL RS" & CV.CV.CVC & kamarat & "plant sp." \\
\hline CV.CVC & rapas & "push through DL RS" & CV.CV.CVC & natatok & "citizen" \\
\hline CV.CVC & rakar & “scratch DL RS" & CV.CV.CVC & malayot & "fish sp." \\
\hline CV.CVC & ratak & “trip DL Rs" & CV.CV.CVC & nafaruk & “wing 1sG DP" \\
\hline CV.CVC & rakpas & "pick flower DL Rs" & CV.CV.CVC & kalakpon & "fish sp." \\
\hline CV.CVC & rataf & "exit DL RS" & CV.CV.CVC & paketan & "go down" \\
\hline CV.CVC & rasak & "sit DL RS" & CV.CV.CVC & tarisal & "driftwood" \\
\hline CV.CVC & ratas & "shave DL RS" & CV.CV.CVC & maloput & "middle" \\
\hline CV.CVC & ralak & “marry DL RS" & CV.CV.CVC & pakelan & "go up" \\
\hline CV.CVC & rasar & "strain DL RS" & CV.CV.CVC & tamarin & "tree sp." \\
\hline CV.CVC & rawat & "hit DL RS" & CV.CV.CVC & memelim & "shellfish sp." \\
\hline CV.CVC & rawas & "be burnt DL RS" & CV.CV.CVVC & tataka:l & "plant sp." \\
\hline CV.CVC & rawal & "control canoe DL RS" & CV.CV.CVVC & tatara:s & "plant sp." \\
\hline CV.CVVC & rapa:k & “delouse DL RS" & CV.CV.CVVC & nalaya:n & "music" \\
\hline CV.CVVC & rakait & "taste DL Rs" & CV.CV.CVVC & maninmast & "bird sp." \\
\hline CV.CVVC & rasa:kp & "make mistake DL Rs" & CV.CV.CVVC & nariwa:k & "tree sp." \\
\hline CV.CVVC & ratair & "be white DL Rs" & CV.CV.CVVC & nataymo:l & "person" \\
\hline CV.CVVC & rasa:l & "swing DL RS" & CV.CV.CVVC & nakpumais & “property" \\
\hline CV.CVVC & rafair & "pick pandanus DL RS" & CV.CV.CVVC & pakofa:m & "shark sp." \\
\hline CV.CVVC & rawa:f & "swim DL Rs" & CV.CV.CVVC & nawora:n & "state of being" \\
\hline CV.CVVC & rawail & “scoop DL RS" & CV.CVV.CVC & rata:pas & "wave DL Rs" \\
\hline CV.CVVC & rasair & "mix DL RS" & CV.CVV.CVC & nakpa:kpak & "banana sp." \\
\hline CV.CVVC & rula:p & "be many DL Rs" & CV.CVV.CVC & raka:kas & "be sweet DL Rs" \\
\hline CVV.CVC & ka:kas & "be sweet" & CV.CVV.CVC & rafa:fat & "believe DL Rs" \\
\hline CVV.CVC & ta:tan & "bury" & CV.CVV.CVC & rataisak & "come ashore DL RS" \\
\hline CVV.CVC & pa:lak & “creep up on” & CV.CVV.CVC & rata:kpas & "be adopted DL Rs" \\
\hline CVV.CVC & ka:fat & "fourth" & CV.CVV.CVC & nmairak & "be clever DL RS" \\
\hline CVV.CVC & ta:pas & "wave" & CV.CVV.CVC & tele:kor & "guard" \\
\hline CVV.CVC & taisak & "come ashore" & CV.CVV.CVC & rapa:lak & "creep up on DL RS" \\
\hline CVV.CVC & takkpas & "be adopted" & CV.CVV.CVVC & nale:nain & "truth" \\
\hline CVV.CVC & fa:fat & "believe" & CV.CVV.CVVC & nale:wa:n & "feast" \\
\hline CVV.CVC & na:pas & "fish sp." & & & \\
\hline CVV.CVC & ymairak & "be clever" & & & \\
\hline CVV.CVC & mailay & "recover" & & & \\
\hline
\end{tabular}




\section{APPENDIX B}

TABLE VI. Results of comparisons (estimated difference, standard error, and $p$-value) for measures of duration (ms), relative RMS amplitude (dB), $f 0$ at $25 \%, 50 \%$, and $75 \%(\mathrm{~Hz})$, and $F 1$ and $F 2$ at midpoints $(\mathrm{Hz})$, for vowel tokens in disyllabic words $(* * *=<0.001 ; * *=<0.01 ; *=<0.05)$.

\begin{tabular}{|c|c|c|c|c|c|c|c|c|c|c|c|c|c|c|c|c|c|c|c|c|c|}
\hline \multirow[b]{2}{*}{ Comparison } & \multicolumn{3}{|c|}{ Dur. } & \multicolumn{3}{|c|}{ Rel. RMS } & \multicolumn{3}{|c|}{ fo $25 \%$} & \multicolumn{3}{|c|}{ f0 50\% } & \multicolumn{3}{|c|}{ f0 $75 \%$} & \multicolumn{3}{|c|}{$F 1$} & \multicolumn{3}{|c|}{$F 2$} \\
\hline & Est & SE & $p$ & Est & SE & $p$ & Est & SE & $p$ & Est & SE & $p$ & Est & SE & $p$ & Est & SE & $p$ & Est & SE & $p$ \\
\hline \multicolumn{22}{|l|}{ Syllable position } \\
\hline syll 1 $\sim$ syll 2 & -5 & 1 & $* * *$ & -0.5 & 0.2 & $*$ & -13 & 1 & $* * *$ & -15 & 1 & $* * *$ & -15 & 1 & $* * *$ & -61 & 6 & $* * *$ & - & - & - \\
\hline \multicolumn{22}{|l|}{$V$ length } \\
\hline $\mathrm{V} \sim \mathrm{V}:$ & -62 & 2 & $* * *$ & -2.2 & 0.3 & $* * *$ & - & - & - & - & - & - & -3 & 1 & $* *$ & -151 & 7 & $* * *$ & -80 & 11 & $* * *$ \\
\hline \multicolumn{22}{|l|}{ Preceding place } \\
\hline alv $\sim$ lab & - & - & - & - & - & - & - & - & - & - & - & - & - & - & - & 27 & 10 & $*$ & 97 & 18 & $* * *$ \\
\hline alv $\sim \mathrm{lbv}$ & - & - & - & - & - & - & - & - & - & - & - & - & - & - & - & 6 & 10 & 1 & 67 & 18 & $* *$ \\
\hline alv $\sim$ vel & - & - & - & - & - & - & - & - & - & - & - & - & - & - & - & 56 & 14 & $* * *$ & 0 & 22 & 1 \\
\hline $\mathrm{lab} \sim \mathrm{lbv}$ & - & - & - & - & - & - & - & - & - & - & - & - & - & - & - & -21 & 12 & 0.55 & -30 & 21 & 0.86 \\
\hline $\mathrm{lab} \sim \mathrm{vel}$ & - & - & - & - & - & - & - & - & - & - & - & - & - & - & - & 29 & 15 & 0.32 & -97 & 23 & $* * *$ \\
\hline $\mathrm{lbv} \sim \mathrm{vel}$ & - & - & - & - & - & - & - & - & - & - & - & - & - & - & - & 50 & 15 & $* *$ & -67 & 24 & $*$ \\
\hline \multicolumn{22}{|l|}{ Preceding manner } \\
\hline apr $\sim$ frc & -21 & 5 & $* * *$ & - & - & - & - & - & - & - & - & - & - & - & - & -107 & 32 & $* *$ & -117 & 16 & $* * *$ \\
\hline apr $\sim$ nsl & 3 & 5 & 1 & - & - & - & - & - & - & - & - & - & - & - & - & 29 & 26 & 1 & -57 & 32 & 0.44 \\
\hline apr $\sim$ stp & -16 & 4 & $* *$ & - & - & - & - & - & - & - & - & - & - & - & - & -95 & 32 & $*$ & -99 & 12 & $* * *$ \\
\hline fre $\sim$ nsl & 23 & 7 & $* *$ & - & - & - & - & - & - & - & - & - & - & - & - & 136 & 40 & $* *$ & 60 & 33 & 0.43 \\
\hline frc $\sim$ stp & 4 & 2 & 0.35 & - & - & - & - & - & - & - & - & - & - & - & - & 12 & 12 & 1 & 18 & 18 & 1 \\
\hline $\mathrm{nsl} \sim \mathrm{stp}$ & -19 & 6 & $*$ & - & - & - & - & - & - & - & - & - & - & - & - & -124 & 39 & $* *$ & -42 & 32 & 1 \\
\hline \multicolumn{22}{|l|}{ Preceding voicing } \\
\hline $\mathrm{vcd} \sim \mathrm{vls}$ & 16 & 4 & $* * *$ & - & - & - & - & - & - & - & - & - & - & - & - & 102 & 34 & $* *$ & - & - & - \\
\hline \multicolumn{22}{|l|}{ Following place } \\
\hline alv $\sim$ lab & -2 & 2 & 1 & - & - & - & 4 & 1 & $* *$ & - & - & - & - & - & - & - & - & - & 49 & 15 & $* *$ \\
\hline $\mathrm{alv} \sim \mathrm{lbv}$ & 7 & 2 & $* *$ & - & - & - & 0 & 1 & 1 & - & - & - & - & - & - & - & - & - & 102 & 18 & $* * *$ \\
\hline alv $\sim$ vel & 9 & 2 & $* * *$ & - & - & - & 0 & 1 & 1 & - & - & - & - & - & - & - & - & - & 35 & 12 & $*$ \\
\hline $\mathrm{lab} \sim \mathrm{lbv}$ & 9 & 3 & $* *$ & - & - & - & -4 & 2 & 0.12 & - & - & - & - & - & - & - & - & - & 53 & 21 & 0.07 \\
\hline $\mathrm{lab} \sim \mathrm{vel}$ & 11 & 2 & $* * *$ & - & - & - & -4 & 1 & 0.07 & - & - & - & - & - & - & - & - & - & -15 & 18 & 1 \\
\hline $\mathrm{lbv} \sim \mathrm{vel}$ & 3 & 3 & 1 & - & - & - & 0 & 2 & 1 & - & - & - & - & - & - & - & - & - & -67 & 19 & $* *$ \\
\hline \multicolumn{22}{|l|}{ Following manner } \\
\hline apr $\sim$ frc & - & - & - & - & - & - & -4 & 1 & $* *$ & - & - & - & - & - & - & - & - & - & -14 & 15 & 1 \\
\hline apr $\sim$ nsl & - & - & - & - & - & - & -6 & 3 & 0.35 & - & - & - & - & - & - & - & - & - & -133 & 32 & $* * *$ \\
\hline apr $\sim$ stp & - & - & - & - & - & - & -2 & 1 & 0.35 & - & - & - & - & - & - & - & - & - & -62 & 12 & $* * *$ \\
\hline fre $\sim$ nsl & - & - & - & - & - & - & -2 & 3 & 1 & - & - & - & - & - & - & - & - & - & -118 & 31 & $* * *$ \\
\hline frc $\sim$ stp & - & - & - & - & - & - & 2 & 1 & 0.78 & - & - & - & - & - & - & - & - & - & -48 & 13 & $* *$ \\
\hline $\mathrm{nsl} \sim \mathrm{stp}$ & - & - & - & - & - & - & 4 & 3 & 1 & - & - & - & - & - & - & - & - & - & 71 & 30 & 0.12 \\
\hline \multicolumn{22}{|l|}{ Following voicing } \\
\hline $\mathrm{vcd} \sim \mathrm{vls}$ & 13 & 2 & $* * *$ & 0.9 & 0.3 & $* *$ & - & - & - & - & - & - & - & - & - & - & - & - & - & - & - \\
\hline Syllable position: $V$ & & & & & & & & & & & & & & & & & & & & & \\
\hline syll $1 \mathrm{~V} \sim \operatorname{syll} 2 \mathrm{~V}$ & -9 & 2 & $* * *$ & -1.0 & 0.3 & $* *$ & - & - & - & - & - & - & - & - & - & -131 & 12 & $* * *$ & - & - & - \\
\hline syll $1 \mathrm{~V} \sim$ syll $1 \mathrm{~V}$ : & -67 & 3 & $* * *$ & -2.8 & 0.4 & $* * *$ & - & - & - & - & - & - & - & - & - & -219 & 14 & $* * *$ & - & - & - \\
\hline syll 1 V syll 2 V: & -67 & 2 & $* * *$ & -2.7 & 0.4 & $* * *$ & - & - & - & - & - & - & - & - & - & -217 & 14 & $* * *$ & - & - & - \\
\hline syll $2 \mathrm{~V} \sim \operatorname{syll} 1 \mathrm{~V}:$ & -57 & 2 & $* * *$ & -1.7 & 0.3 & $* * *$ & - & - & - & - & - & - & - & - & - & -88 & 10 & $* * *$ & - & - & - \\
\hline syll 2 V syll 2 V: & -57 & 2 & $* * *$ & -1.6 & 0.4 & $* * *$ & - & - & - & - & - & - & - & - & - & -86 & 10 & $* * *$ & - & - & - \\
\hline syll $1 \mathrm{~V}: \sim$ syll $2 \mathrm{~V}$ : & 0 & 2 & 1 & 0.1 & 0.4 & 1 & - & - & - & - & - & - & - & - & - & 2 & 13 & 1 & - & - & - \\
\hline
\end{tabular}




\section{APPENDIX C}

TABLE VII. Results of comparisons (estimated difference, standard error, and $p$-value) for measures of duration (ms), relative RMS amplitude (dB), $f 0$ at $25 \%, 50 \%$, and $75 \%(\mathrm{~Hz})$, and $F 1$ and $F 2$ at midpoints $(\mathrm{Hz})$, for vowel tokens in trisyllabic words $(* * *=<0.001 ; * *=<0.01 ; *=<0.05)$.

\begin{tabular}{|c|c|c|c|c|c|c|c|c|c|c|c|c|c|c|c|c|c|c|c|c|c|}
\hline \multirow[b]{2}{*}{ Comparison } & \multicolumn{3}{|c|}{ Dur. } & \multicolumn{3}{|c|}{ Rel. RMS } & \multicolumn{3}{|c|}{ f0 25\% } & \multicolumn{3}{|c|}{$f 050 \%$} & \multicolumn{3}{|c|}{$f 075 \%$} & \multicolumn{3}{|c|}{$F 1$} & \multicolumn{3}{|c|}{$F 2$} \\
\hline & Est & SE & $p$ & Est & SE & $p$ & Est & SE & $p$ & Est & SE & $p$ & Est & SE & $p$ & Est & SE & $p$ & Est & SE & $p$ \\
\hline \multicolumn{22}{|l|}{ Syll.position } \\
\hline syll $1 \sim$ syll 2 & -2 & 1 & 0.73 & - & - & - & -2 & 1 & 0.09 & -3 & 1 & $*$ & -3 & 1 & $*$ & - & - & - & - & - & - \\
\hline syll $1 \sim$ syll 3 & -6 & 2 & $* *$ & - & - & - & -18 & 1 & $* * *$ & -19 & 1 & $* * *$ & -21 & 1 & $* * *$ & - & - & - & - & - & - \\
\hline syll $2 \sim$ syll 3 & -4 & 1 & $* *$ & - & - & - & -16 & 1 & $* * *$ & -17 & 1 & $* * *$ & -18 & 1 & $* * *$ & - & - & - & - & - & - \\
\hline \multicolumn{22}{|l|}{$V$ length } \\
\hline $\mathrm{V} \sim \mathrm{V}:$ & -68 & 1 & $* * *$ & -1.5 & 0.3 & $* * *$ & 5 & 1 & $* * *$ & 5 & 1 & $* * *$ & 4 & 1 & $* * *$ & -98 & 7 & $* * *$ & -73 & 11 & $* * *$ \\
\hline \multicolumn{22}{|l|}{ Preceding place } \\
\hline alv $\sim$ lab & 2 & 2 & 1 & - & - & - & - & - & - & - & - & - & - & - & - & - & - & - & 148 & 15 & $* * *$ \\
\hline alv $\sim \mathrm{lbv}$ & 3 & 2 & 0.76 & - & - & - & - & - & - & - & - & - & - & - & - & - & - & - & 79 & 18 & $* * *$ \\
\hline alv $\sim$ vel & 10 & 2 & $* * *$ & - & - & - & - & - & - & - & - & - & - & - & - & - & - & - & 42 & 19 & 0.18 \\
\hline $\mathrm{lab} \sim \mathrm{lbv}$ & 1 & 3 & 1 & - & - & - & - & - & - & - & - & - & - & - & - & - & - & - & -69 & 22 & $* *$ \\
\hline lab $\sim \mathrm{vel}$ & 8 & 2 & $* *$ & - & - & - & - & - & - & - & - & - & - & - & - & - & - & - & -106 & 22 & $* * *$ \\
\hline $\mathrm{lbv} \sim \mathrm{vel}$ & 6 & 3 & 0.07 & - & - & - & - & - & - & - & - & - & - & - & - & - & - & - & -37 & 22 & 0.57 \\
\hline \multicolumn{22}{|l|}{ Preceding manner } \\
\hline apr $\sim$ frc & -4 & 3 & 1 & - & - & - & - & - & - & - & - & - & - & - & - & - & - & - & -48 & 24 & 0.29 \\
\hline apr $\sim \mathrm{nsl}$ & -9 & 2 & $* * *$ & - & - & - & - & - & - & - & - & - & - & - & - & - & - & - & -90 & 16 & $* * *$ \\
\hline apr $\sim$ stp & -5 & 2 & $*$ & - & - & - & - & - & - & - & - & - & - & - & - & - & - & - & -20 & 14 & 0.92 \\
\hline frc $\sim$ nsl & -5 & 3 & 0.59 & - & - & - & - & - & - & - & - & - & - & - & - & - & - & - & -42 & 24 & 0.47 \\
\hline frc $\sim \operatorname{stp}$ & -1 & 3 & 1 & - & - & - & - & - & - & - & - & - & - & - & - & - & - & - & 28 & 22 & 1 \\
\hline $\mathrm{nsl} \sim \operatorname{stp}$ & 4 & 2 & 0.08 & - & - & - & - & - & - & - & - & - & - & - & - & - & - & - & 69 & 15 & $* * *$ \\
\hline \multicolumn{22}{|l|}{ Preceding voicing } \\
\hline $\mathrm{ved} \sim \mathrm{vls}$ & - & - & - & - & - & - & -3 & 1 & $* *$ & - & - & - & - & - & - & - & - & - & - & - & - \\
\hline \multicolumn{22}{|l|}{ Following place } \\
\hline alv $\sim$ lab & 4 & 2 & 0.57 & - & - & - & - & - & - & - & - & - & - & - & - & - & - & - & 24 & 19 & 1 \\
\hline alv $\sim \mathrm{lbv}$ & 11 & 2 & $* * *$ & - & - & - & - & - & - & - & - & - & - & - & - & - & - & - & 63 & 16 & $* * *$ \\
\hline alv $\sim$ vel & 6 & 2 & $* * *$ & - & - & - & - & - & - & - & - & - & - & - & - & - & - & - & 36 & 14 & 0.05 \\
\hline $\mathrm{lab} \sim \mathrm{lbv}$ & 7 & 3 & 0.08 & - & - & - & - & - & - & - & - & - & - & - & - & - & - & - & 39 & 24 & 0.63 \\
\hline $\mathrm{lab} \sim \mathrm{vel}$ & 3 & 3 & 1 & - & - & - & - & - & - & - & - & - & - & - & - & - & - & - & 12 & 24 & 1 \\
\hline $\mathrm{lbv} \sim \mathrm{vel}$ & -5 & 2 & 0.25 & - & - & - & - & - & - & - & - & - & - & - & - & - & - & - & -27 & 17 & 0.68 \\
\hline Following & & & & & & & & & & & & & & & & & & & & & \\
\hline apr $\sim$ frc & -4 & 2 & 0.52 & 2.2 & 0.4 & $* * *$ & - & - & - & - & - & - & - & - & - & - & - & - & -9 & 19 & 1 \\
\hline apr $\sim \mathrm{nsl}$ & 3 & 2 & 0.72 & 0.4 & 0.3 & 0.94 & - & - & - & - & - & - & - & - & - & - & - & - & -27 & 16 & 0.51 \\
\hline apr $\sim$ stp & 4 & 2 & 0.06 & 1.4 & 0.3 & $* * *$ & - & - & - & - & - & - & - & - & - & - & - & - & 32 & 15 & 0.21 \\
\hline frc $\sim \mathrm{nsl}$ & 7 & 2 & $*$ & -1.8 & 0.4 & $* * *$ & - & - & - & - & - & - & - & - & - & - & - & - & -18 & 18 & 1 \\
\hline frc $\sim$ stp & 8 & 2 & $* * *$ & -0.8 & 0.4 & 0.15 & - & - & - & - & - & - & - & - & - & - & - & - & 41 & 16 & 0.06 \\
\hline $\mathrm{nsl} \sim \mathrm{stp}$ & 1 & 2 & 1 & 1.0 & 0.3 & $* *$ & - & - & - & - & - & - & - & - & - & - & - & - & 59 & 15 & $* * *$ \\
\hline Syllable $p$ & & & & & & & & & & & & & & & & & & & & & \\
\hline syll $1 \mathrm{~V} \sim$ syll $2 \mathrm{~V}$ & - & - & - & - & - & - & - & - & - & - & - & - & - & - & - & 49 & 9 & $* * *$ & 29 & 14 & 0.25 \\
\hline syll $1 \mathrm{~V} \sim \operatorname{syll} 3 \mathrm{~V}$ & - & - & - & - & - & - & - & - & - & - & - & - & - & - & - & -26 & 9 & $*$ & -38 & 16 & 0.13 \\
\hline syll $1 \mathrm{~V} \sim$ syll $2 \mathrm{~V}$ : & - & - & - & - & - & - & - & - & - & - & - & - & - & - & - & -120 & 11 & $* * *$ & -92 & 16 & $* * *$ \\
\hline syll $1 \mathrm{~V} \sim \operatorname{syll} 3 \mathrm{~V}$ : & - & - & - & - & - & - & - & - & - & - & - & - & - & - & - & -61 & 9 & $* * *$ & -59 & 16 & $* *$ \\
\hline syll $2 \mathrm{~V} \sim$ syll $3 \mathrm{~V}$ & - & - & - & - & - & - & - & - & - & - & - & - & - & - & - & -75 & 12 & $* * *$ & -67 & 19 & $* *$ \\
\hline syll 2 V $\sim$ syll 2 V: & - & - & - & - & - & - & - & - & - & - & - & - & - & - & - & -169 & 13 & $* * *$ & -121 & 19 & $* * *$ \\
\hline syll $2 \mathrm{~V} \sim \operatorname{syll} 3 \mathrm{~V}:$ & - & - & - & - & - & - & - & - & - & - & - & - & - & - & - & -110 & 12 & $* * *$ & -88 & 21 & $* * *$ \\
\hline syll 3 V $\sim$ syll 2 V: & - & - & - & - & - & - & - & - & - & - & - & - & - & - & - & -94 & 12 & $* * *$ & -54 & 17 & $*$ \\
\hline syll $3 \mathrm{~V} \sim \operatorname{syll} 3 \mathrm{~V}:$ & - & - & - & - & - & - & - & - & - & - & - & - & - & 一 & - & -35 & 12 & $*$ & -22 & 20 & 0.80 \\
\hline syll $2 \mathrm{~V}: \sim \operatorname{syll} 3 \mathrm{~V}$ : & - & - & - & - & - & - & - & - & - & - & - & - & - & - & - & 59 & 13 & $* * *$ & 33 & 22 & 0.58 \\
\hline
\end{tabular}

${ }^{1}$ Emae, Futuna-Aniwa, and Mele-Fila are Polynesian (Central Pacific) languages spoken in Vanuatu, and Bislama is an English-lexified creole which is a lingua franca in Vanuatu, and English and French are learned as additional languages by many people.

${ }^{2}$ These nine trisyllabic word tokens with seemingly different prosodic patterns relate to five different lexical items. Three were produced by participant GK and six by participant MJ. They were not a consistent set, but the primary difference was that in these cases it was not the final syllables which were impressionistically most prominent. For the six tokens from participant MJ, the full utterance they were embedded in exhibited a marked rise on the final word sernrak "usually" (which followed the target word), in comparison to the falling declarative pattern typically used 
by the participants. Three tokens were also produced with a pause preceding the target word. Two of the three tokens produced by GK were also preceded by a short pause, though the three utterances maintained the overall falling intonation pattern.

Bates, D., Mächler, M., Bolker, B. M., and Walker, S. C. (2015). "Fitting linear mixed-effects models using lme4," J. Stat. Software 67(1), 1-48.

Beckman, M. (1986). Stress and Non-stress Accent (Foris Publications, Dordrecht, The Netherlands).

Berinstein, A. E. (1979). "A cross-linguistic study on the perception and production of stress," UCLA Work. Papers Phonetics 47, 1-59.

Billington, R. (2017). "Rosey Billington Nafsan materials (BR1), Digital collection managed by PARADISEC," http://catalog.paradisec.org.au/collections/BR1.

Billington, R., Fletcher, J., Thieberger, N., and Volchok, B. (2018). "Acoustic correlates of prominence in Nafsan," in Proceedings of the 17th Australasian International Speech Science and Technology Conference, edited by J. Epps, J. Wolfe, J. Smith, and C. Jones (Australasian Speech Science and Technology Association, Sydney, Australia), pp. 137-140

Billington, R., Thieberger, N., and Fletcher, J. (2020). "Phonetic evidence for phonotactic change in Nafsan (South Efate)," Ital. J. Linguist. (Special issue: The Dynamics of Vowel Reduction and Loss: Phonetic Mechanisms and Phonological Outcomes) (in press).

Boersma, P., and Weenink, D. (2018). "Praat," Version 6.0.40, available at http://www.praat.org.

Calhoun, S. (2015). "The interaction of prosody and syntax in Samoan focus marking," Lingua 165, 205-229.

Calhoun, S. (2017). "Exclusives, equatives and prosodic phrases in Samoan," Glossa 2(1), 11

Capell, A. (1935-1980). "The Nguna-Efate dialects," http://catalog.paradisec.org.au/repository/AC2/VNEFAT11 (Last viewed 15 September 2019)

Clark, R. (1985). “The Efate dialects," Te Reo 28, 3-35.

Clemens, L. (2014). "The prosody of Niuean pseudo noun incorporation: A recursion-based analysis," in Proceedings of the 44th Meeting of the North East Linguistic Society, edited by J. Iyer and L. Kusmer (Graduate Student Linguistic Association, Amherst, MA), pp. 69-82.

Clemens, L. (2019). "Prosodic noun incorporation: The relationship between prosody and argument structure in Niuean," Syntax 22(4), 337-377.

Crowley, T. (1982). The Paamese Language of Vanuatu (Pacific Linguistics, Canberra, Australia).

Crowley, T. (1998). An Erromangan (Sye) Grammar (University of Hawaii Press, Honolulu, HI).

Crowley, T. (2006). Naman: A Vanishing Language of Malakula (Vanuatu) (Pacific Linguistics, Canberra, Australia)

Cutler, A. (2005). "Lexical stress," in The Handbook of Speech Perception, edited by D. B. Pisoni and R. E. Remez (Blackwell, Oxford, England), pp. 264-289.

Dimock, L. (2009). “A grammar of Nahavaq (Malakula, Vanuatu)," Ph.D. thesis, Victoria University of Wellington, Wellington, New Zealand.

Dogil, G., and Williams, B. (1999). "The phonetic manifestation of word stress," in Word Prosodic Systems in the Languages of Europe, edited by H. van der Hulst (De Gruyter Mouton, Berlin, Germany), pp. 273-334.

Fletcher, J., Billington, R., and Thieberger, N. (2019). "Prosodic marking of focus in Nafsan," in Proceedings of the 19th International Congress of Phonetic Sciences, Melbourne, Australia, edited by S. Calhoun, P. Escudero, M. Tabain, and P. Warren (Australasian Speech Science and Technology Association, Canberra, Australia), pp. 1764-1758.

François, A. (2001). "Contraintes de structures et liberté dans l'organisation du discours: Une description du mwotlap, langue océanienne du Vanuatu" ("Structural constraints and freedom in speech elaboration: A description of Mwotlap, an Oceanic language of Vanuatu"), Ph.D. thesis, Université Paris-Sorbonne, Paris, France.

François, A. (2005). "Unraveling the history of the vowels of seventeen Northern Vanuatu languages," Oceanic Ling. 44(2), 443-504.

Garellek, M., and White, J. (2015). "Phonetics of Tongan stress," J. Intl. Phon. Assoc. 45(1), 13-34.

Goedemans, R. (2010). "A typology of stress patterns," in A Survey of Word Accentual Patterns in the Languages of the World, edited by H. van der Hulst, R. Goedemans, and E. van Zanten (De Gruyter Mouton, Berlin, Germany), pp. 647-668.

Gordon, M. (2002). "A phonetically driven account of syllable weight," Language 78(1), 51-80.

Gordon, M. K., and Roettger, T. (2017). "Acoustic correlates of word stress: A cross-linguistic survey,” Ling. Vanguard 3(1), 1-11.

Guérin, V. (2019). "Recapitulative linkage in Mavea," in Bridging Constructions, edited by V. Guérin (Language Science Press, Berlin, Germany), pp. 207-238.

Gussenhoven, C. (2012). "Quantity or durational enhancement of tone: The case of Maastricht Limburgian high vowels," in Phonological Explorations: Empirical, Theoretical and Diachronic Issues, edited by B. Botman and R. Noske (De Gruyter Mouton, Berlin, Germany), pp. 241-253.

Guy, J. B. M. (1974). A Grammar of the Northern Dialect of Sakao (Pacific Linguistics, Canberra, Australia).

Healey, D. S. (2013). "A grammar of Maskelynes: The language of Uluveu Island, Vanuatu," Ph.D. thesis, The University of the South Pacific, Port Vila, Vanuatu.

Himmelmann, N. P., and Kaufman, D. (2020). "Prosodic systems: Austronesia," in The Oxford Handbook of Prosody, edited by C. Gussenhoven and A. Chen (Oxford University Press, Oxford, England) (in press).

Jepson, K. (2014). "Intonational marking of focus in Torau," in Selected Papers from the 44th Conference of the Australian Linguistic Society, edited by L. Gawne and J. Vaughan (University of Melbourne, Melbourne, Australia), pp. 261-282.

Jun, S.-A. (1998). "The accentual phrase in the Korean prosodic hierarchy," Phonology 15(2), 189-226.

Jun, S.-A., and Fougeron, C. (2002). "Realizations of accentual phrase in French intonation," Probus 14, 147-172.

Kaland, C. (2019). "Acoustic correlates of word stress in Papuan Malay," J. Phonetics 74, 55-74.

Kisler, T., Reichel, U., and Schiel, F. (2017). "Multilingual processing of speech via web services," Comp. Speech Lang. 45, 326-347.

Krajinović, A., Billington, R., Emil, L., Kaltap̃au, G., and Thieberger, N. (2019). "Building capacity for community-led documentation in Erakor, Vanuatu," in Human Language Technologies as a Challenge for Computer Science and Linguistics-2019 (Proceedings of the 9th Language and Technology Conference), edited by Z. Vetulani and P. Paroubek (Wydawnictwo Nauka i Innowacje, Poznań, Poland), pp. 185-189.

Kuo, G., and Vicenik, C. (2012). "The intonation of Tongan," UCLA Work. Papers Phonetics 111, 63-91.

Kuznetsova, A., Brockhoff, P. B., and Christensen, R. H. B. (2017). "ImerTest package: Tests in linear mixed effects models," J. Stat. Software 82(13), 1-26.

Lacrampe, S. (2014). "Lelepa: Topics in the grammar of a Vanuatu language," Ph.D. thesis, Australian National University, Canberra, Australia.

Lehiste, I. (1970). Suprasegmentals (MIT, Oxford, England).

Lunden, A., Campbell, J., Hutchens, M., and Kalivoda, N. (2017). "Vowellength contrasts and phonetic cues to stress: An investigation of their relation," Phonology 34, 565-580.

Lynch, J. (2000a). A Grammar of Anejom (Pacific Linguistics, Canberra, Australia).

Lynch, J. (2000b). "Reconstructing Proto-Oceanic stress," Oceanic Ling. 39(1), 53-82.

Lynch, J. (2000c). "South Efate phonological history," Oceanic Ling. 39(2), 320-338.

Lynch, J., Ross, M., and Crowley, T. (2002). The Oceanic Languages (Curzon Press, Richmond, England).

Malau, C. (2016). A Grammar of Vurës, Vanuatu (De Gruyter, Berlin, Germany). McDonnell, B. (2016). "Acoustic correlates of stress in Besemah," NUSA: Stud. Lang. Typol. Change 60, 1-28.

Mixdorff, H., Watson, C., and Keegan, P. (2018). "Quantitative analysis of Māori prosody from three generations," in Proceedings of the 9th International Conference on Speech Prosody, edited by K. Klessa, J. Bachan, A. Wagner, M. Karpiński, and D. Śledziński, pp. 631-635.

$\mathrm{R}$ Core Team (2018). "R: A language and environment for statistical computing," Version 3.4.2, available at https://www.r-project.org/.

Riehl, A. K., and Jauncey, D. G. (2005). “Tamambo," J. Intl. Phon. Assoc. 35(2), 255-259. 
Ross, M. (1998). "Proto-Oceanic phonology and morphology, Vol. 1: Material culture," in The Lexicon of Proto-Oceanic, edited by M. Ross, A. Pawley, and M. Osmond (Pacific Linguistics, Canberra, Australia), pp. 15-35.

Schütz, A. (1969). Nguna Grammar (University of Hawaii Press, Honolulu, HI).

Simard, C., and Wegener, C. (2017). "Fronted NPs in a verb-initial language - clause-internal or external? Prosodic cues to the rescue!," Glossa 2(1), 1-32.

Sperlich, W. B. (1991). "Namakir: A description of a Central Vanuatu language," Ph.D. thesis, University of Auckland, Auckland, New Zealand.

Thieberger, N. (2006). A Grammar of South Efate: An Oceanic Language of Vanuatu (University of Hawaii Press, Honolulu, HI).

Thieberger, N. (2011a). Natrauswen nig Efat: Stories from South Efate (University of Melbourne, Melbourne, Australia).

Thieberger, N. (2011b). A South Efate Dictionary (University of Melbourne, Melbourne, Australia).

Thompson, L., Watson, C., Harlow, R., King, J., Maclagan, M., Charters, H., and Keegan, P. (2011). "Phrases, pitch and perceived prominence in Māori," in Proceedings of Interspeech 2011, edited by P. Cosi, R. De Mori, G. Di Fabbrizio, and R. Pieraccini, ISCA, Florence, Italy, pp. 1365-1368.

Torres, C., Fletcher, J., and Wigglesworth, G. (2018). "Investigating word prominence in Drehu," in Proceedings of the 17th Australasian International Speech Science and Technology Conference, edited by J. Epps, J. Wolfe, J. Smith, and C. Jones (Australasian Speech Science and Technology Association, Sydney, Australia), pp. 141-144.

Tryon, D. T. (1976). New Hebrides Languages: An Internal Classification (Pacific Linguistics, Canberra, Australia). van Heuven, V. (2019). "Acoustic correlates and perceptual cues of word and sentence stress: Towards a cross-linguistic perspective," in The Study of Word Stress and Accent: Theories, Methods and Data, edited by R. Goedemans, J. Heinz, and H. van der Hulst (Cambridge University Press, Cambridge, England), pp. 15-59.

van Heuven, V., and Sluijter, A. (1996). "Notes on the phonetics of word prosody," in Stress Patterns of the World, Part 1: Background, edited by R. Goedemans, H. van der Hulst, and E. Visch (Holland Academic Graphics, The Hague, The Netherlands), pp. 233-269.

van Heuven, V., and Turk, A. (2020). "Phonetic correlates of word and sentence stress," in The Oxford Handbook of Prosody, edited by C. Gussenhoven and A. Chen (Oxford University Press, Oxford, England) (in press).

Vogel, I., Athanasopoulou, A., and Pincus, N. (2016). "Prominence, contrast and the functional load hypothesis: An acoustic investigation," in Dimensions of Phonological Stress, edited by J. Heinz, R. Goedemans, and H. van der Hulst (Cambridge University Press, Cambridge, England), pp. 123-167.

von Prince, K. (2015). A Grammar of Daakaka (De Gruyter Mouton, Berlin, Germany).

Winkelmann, R., Harrington, J., and Jänsch, K. (2017). "EMU-SDMS: Advanced speech database management and analysis in R," Comp. Speech Lang. 45, 392-410.

Winkelmann, R., Jänsch, K., Cassidy, S., and Harrington, J. (2018). "emuR: Main package of the EMU Speech Database Management System," R package, Version 1.0.0.

Yu, K. M., and Stabler, E. P. (2017). "(In)variability in the Samoan syntax/ prosody interface and consequences for syntactic parsing," Lab. Phonol. 8(1), 1-44.

Zuraw, K., Yu, K. M., and Orfitelli, R. (2014). "The word-level prosody of Samoan," Phonology 31(2), 271-327. 